\title{
Application of Polymeric Nanocarriers for Enhancing the Bioavailability of Antibiotics at the Target Site and Overcoming Antimicrobial Resistance
}

\author{
Hung Le $\mathbb{B}^{\text {, }}$, Carole Karakasyan, Thierry Jouenne, Didier Le Cerf * ${ }^{*}$ and Emmanuelle Dé
}

Citation: Le, H.; Karakasyan, C.; Jouenne, T.; Le Cerf, D.; Dé, E. Application of Polymeric Nanocarriers for Enhancing the Bioavailability of Antibiotics at the Target Site and Overcoming Antimicrobial Resistance. Appl. Sci. 2021, 11, 10695. https://doi.org/ 10.3390/app112210695

Academic Editors:

Gianpiero Calabrese

and Manuela Pintado

Received: 24 September 2021

Accepted: 8 November 2021

Published: 12 November 2021

Publisher's Note: MDPI stays neutral with regard to jurisdictional claims in published maps and institutional affiliations.

Copyright: (c) 2021 by the authors. Licensee MDPI, Basel, Switzerland. This article is an open access article distributed under the terms and conditions of the Creative Commons Attribution (CC BY) license (https:// creativecommons.org/licenses/by/ $4.0 /)$.
Laboratory Polymers, Biopolymers \& Surfaces, Normandie Université, UNIROUEN, INSA Rouen, CNRS, PBS, 76000 Rouen, France; hung.le1@univ-rouen.fr (H.L.); carole.karakasyan@univ-rouen.fr (C.K.); thierry.jouenne@univ-rouen.fr (T.J.); emmanuelle.de@univ-rouen.fr (E.D.)

* Correspondence: didier.lecerf@univ-rouen.fr; Tel.: +33-235146543

\begin{abstract}
Antimicrobial resistance is one of the greatest threats to global health. Although the efforts in antibiotic drug discovery continue to play a pivotal role, this solution alone probably will not be enough to ensure the required level of infection control in the future. New strategies and innovative modes of action are desperately needed to preserve the effectiveness of antimicrobials. Accordingly, antibiotic delivery based on polymeric nanoparticles is one of the possible methods that has been recently explored to improve their pharmacokinetic profile. Through optimized access of antibiotics to their sites of action, nanocarriers can unlock the full potential of the antibiotic cargoes, extend the antimicrobial spectrum, and reduce the required dose of antibiotic while preserving efficacy. Additionally, the use of an antibiotic-loaded nanocarrier is also considered a steady solution as novel molecules can be continuously developed and incorporated into the delivery platform. This review describes the present state of polymeric nanocarriers in enhancing antibiotic treatment, including improved pharmacokinetic properties and restored antibiotic efficacy against drug-resistant bacteria. Additionally, the current challenges and the future direction of this field are discussed.
\end{abstract}

Keywords: antimicrobial resistance; polymeric nanocarrier; antibiotic; local bioavailability; controlled release; targeted delivery; co-delivery; antibiotic combination

\section{Introduction}

Antibiotic resistance is one of the greatest threats to human health today. Although efforts have been made to ensure a sustainable flow of new antibacterial drugs, especially those with novel mechanisms of action, the emergence and spread of antibiotic resistance seems inevitable. Through mutation and selection, most pathogenic microorganisms can be adapted and develop defenses against antibiotic attacks. As the threat of antibiotic resistance spreads, the need for more advanced approaches and overcoming the mechanisms behind antibiotic resistance become essential [1].

Instead of entering into the typical cycle of new antimicrobial resistance, another proposed strategy to overcome resistance is to optimize the delivery or otherwise enhance the accessibility of antibiotics to their sites of action. In fact, the ability of antibiotics to reach the target sites, namely, local or bacterial bioavailability, is a key determinant of clinical outcome [2]. A sufficient exposure level of antibiotics kills pathogenic bacteria before they have the chance to evolve drug resistance. However, the current administration of antibiotics still faces a series of complex transport barriers, from the tissue level to the intra-bacterial level, that significantly compromises this therapeutic purpose [3].

For example, most infections do not occur in the bloodstream (other than sepsis) but, rather, in a specific tissue site. Thus, even though the required plasma concentrations of antibiotics are achieved, the indiscriminate diffusion of systemic antibiotics causes offtarget drug loss, limiting the effective dosage at the infectious tissues. Moreover, most 
bacteria grow in matrix-enclosed biofilms, representing a physical barrier that can delay the penetration of the antimicrobial agent [4]. Additionally, various bacteria can take shelter and persist in mammalian cells, causing persistent or recurrent infections. However, the current treatment of intracellular infections remains challenged mainly due to the poor intracellular penetration of most antibiotics [5].

Ultimately, bacteria possess diverse defense systems (intrinsic or adaptive) against the penetration of toxic xenobiotics or render them ineffective [6]. For instance, some bacterial enzymes can modify or destroy the active compound, rendering the antibiotic unable to interact with its site of action (e.g., AmpC $\beta$-lactamases). For antibiotic compounds with targets located in the cytoplasm, the membrane barriers, particularly the outer membrane of Gram-negative bacteria, can inhibit their penetration (e.g., reductions in antibiotic transport porin expression). Once an antibiotic has successfully entered the cell, it will then face bacterial efflux pumps (membrane proteins) that extrude these xenobiotics back outside the cell before reaching their target (e.g., NorA, LmrS in Staphylococcus aureus, AcrB in Escherichia coli, MexB in Pseudomonas aeruginosa). All of these mechanisms create a concentration gradient of antibiotics dwindling from the outside environment to the interior of the bacterial cell. Notably, the spatiotemporal heterogeneity in the antibiotic exposure has been shown to facilitate the antibiotic resistance evolution and enable pathogenic populations to obtain a higher level of resistance than in homogeneous antibiotic concentrations [7].

Collectively, all these obstacles highlight the need for research to find effective antibiotic delivery platforms. A suitable dosage form of antibiotics improves not only therapeutic efficacy but also reduces off-target effects, systemic toxicity, and the development of resistance, thereby extending the lifespan of current antibiotics. This is crucial, at least in the short term, as novel antibiotics are not likely to enter widespread clinical practice in the immediate future $[8,9]$.

In this context, polymeric nanoparticles (NPs) are attractive as an effective antibiotic delivery vehicle for obtaining desirable drug-like pharmacokinetic properties [10]. Driven by breakthroughs in biotechnologies and polymer synthesis, developed polymeric nanocarriers can currently address most of the above-cited challenges related to free-form antibiotic delivery. Various nanocarrier platforms have been explored to improve the physicochemical properties of antimicrobials (dissolution and stability), precisely release them at the infectious sites in a controlled manner, and co-deliver the antibiotic combinations (Figure 1). Besides the potential therapeutic benefits, polymer nanocarriers are commonly synthesized from biodegradable and biocompatible materials, facilitating the transfer of these novel antibiotic dosage forms to clinical practice.

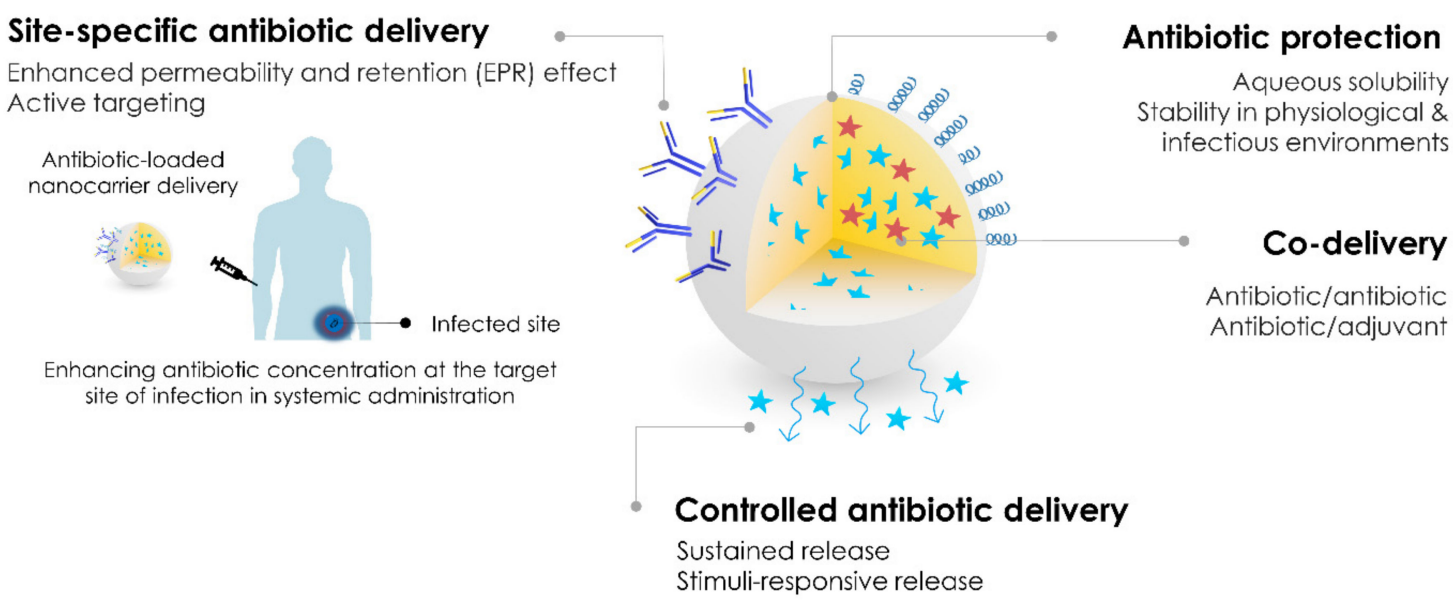

Figure 1. Overview highlighting the main advantages of a nanocarrier-based antibiotic delivery approach for the treatment of bacterial infections. Depending on the targeted therapeutic applications, nanocarriers may be engineered to improve different pharmacokinetic parameters of antibiotics, resulting in increased therapeutic efficacy and reduced adverse side effects. 
In this review, we will describe the essential aspects in which polymeric nanocarriers can be engineered to offer better local bioavailability and maximize antibiotic-therapeutic efficacy. The intrinsic antibacterial mechanisms of nanomaterials have been summarized in several recent reviews $[8,9,11]$ and, thus, will not be reiterated in detail here. The engineering approaches discussed will include dissolution and stability enhancement of antimicrobial compounds, Controlled antibiotic delivery, Targeting delivery of antibiotics to sites of infection, and Co-delivery platforms for combination antibiotic therapy. The current challenge and future direction of nanocarrier-based drug delivery systems for antimicrobial therapy are also discussed.

\section{Dissolution and Stability Enhancement of Antimicrobial Compounds}

The formulation of poorly soluble and unstable drugs is a major challenge for pharmaceutical scientists. The poor water solubility of many antibiotics (Classes II and IV, according to the biopharmaceutical classification system) are associated with several serious problems, such as poor absorption, aggregation, or precipitation during the administration, which may reduce their bioavailability and produce undesirable side effects [12,13]. In addition, the removal of antibiotics from the blood before reaching the infected tissue causes a prolonged exposure of bacteria to low levels of antibiotics, raising the risk for antibiotic resistance emergence. In this context, polymeric nanocarriers with unique physicochemical properties, especially a high surface-to-volume ratio, constitute a promising platform for overcoming these drug delivery limitations.

By packaging the antimicrobials in a polymeric matrix, many nano-formulations have been used to increase efficacy and reduce adverse reactions by altering the physicochemical properties of the original drugs. For example, Durairaj et al. described a guanidinylated dendrimeric vehicle for gatifloxacin, a zwitterionic antibiotic with a $\mathrm{pH}$-dependent solubility profile [14]. The resulting dendrimer complex increased gatifloxacin solubility by up to four fold and presented a greater rate of drug transport into the intraocular tissues during the short precorneal residence of drop formulation. In addition, the nano-formulation exhibited a 2 to 4 times faster killing rate in comparison to antibiotic solution against the resistant strain of methicillin-resistant S. aureus (MRSA), which is commonly found in the conjunctiva. Likewise, Liu et al. recently developed supramolecular hydrogel nano-antibiotics by conjugating small-molecule antibacterial triclosan to self-assembling peptides [15]. The resultant nano-antibiotics presented increased triclosan solubility by 850 fold. Furthermore, the nano-antibiotics smoothly accumulated at the bacterial infection site after intravenous injection and exhibited enhanced antibacterial activities with low side effects. Similarly, nano-encapsulation has also been applied to rescue various antimicrobials with disfavorable pharmacokinetic profiles such as ciprofloxacin [16], chloramphenicol [17], roxithromycin [18], essential oils [19,20], and curcumin [21].

In addition to solubility limitations, poor stability may also limit the bioavailability of many drugs. Antimicrobial peptides (AMPs) have emerged in recent years as a promising substitute for conventional antibiotics. However, due to low stability in the ionic strength environment, efficient delivery of AMPs to their action sites remains a major obstacle, which significantly hampers their clinical application [22]. In this regard, polymeric nanoplatforms may serve as a protective layer to antibiotics against environmental degradation, protect them from body clearance, and maintain sustainable therapeutic concentrations to achieve efficient treatments $[23,24]$. For instance, in an attempt to overcome the peptide degradation by the harsh gut environment and ensure its bioavailability on oral administration, Rishi et al. developed an encapsulated system based on chitosan NPs for cryptdin-2 (a Paneth cell AMP) [24]. A developed nanocarrier system provided optimal stability of the active ingredient in gastrointestinal conditions and successful delivery of cryptdin-2 across the gut wall. In a mouse model of Salmonella infection, the treatment of encapsulated peptide enhanced survival rates up to $83 \%$ versus $100 \%$ mortality observed with the free peptide. Alternatively, the inclusion of AMPs into polymeric NPs can also minimize undesirable interactions between their cationic residues with host cells, thereby reducing 
the required AMP dose and its systemic toxicity. For example, to reduce Colistin-induced nephrotoxicity and neurotoxicity, Yang et al. designed antibiotic cross-linked micelles based on the Pluronic F127 block copolymers [25]. The authors showed that Colistinencapsulated micelles exhibited an improved safety profile, with a maximum tolerated dose in mice $(100 \mathrm{mg} / \mathrm{kg})$ at least 16 times higher than the free drug, while preserving bactericidal activity.

Similarly, antimicrobial gene therapies, such as antisense strategy [26], transcription factor decoys [27], or CRISPR-Cas systems [28], have recently attracted enormous attention and opened new avenues to overcome multidrug resistance and restore antibiotic susceptibility. However, their therapeutic potential requires an efficient mechanism of entry of the gene agents into the bacterial cell, which is inherently a hurdle because of their poor stability, rapid clearance in blood circulation, and lack of targeting ability. In the same way, to overcome these drawbacks, many types of NPs' platforms have been developed as carriers that afford efficient oligonucleotide protection against nucleases and deliver them to the target site $[29,30]$.

Apart from improving physicochemical properties, nanocarriers have also been explored to protect antibiotics from the inactivation effects of bacterial enzymes, thereby circumventing antibiotic resistance mechanism. For example, in a study by Turos et al., coating penicillin $\mathrm{G}$ in polyacrylate NPs not only enhanced water solubility but also rejuvenated the in vivo antibacterial activity of penicillin against $\beta$-lactamase producing microbes such as MRSA [31]. Likewise, the incorporation of imipenem into poly $\varepsilon$-caprolactone (PCL) and polylactide-co-glycolide (PLGA) nanocapsules protected the loaded antibiotic from extracellular carbapenemases and lowered the mutation prevention concentration of free imipenem [32].

In another example mentioned above, the extracellular polymeric substances (EPS) in biofilms, such as polysaccharides and extracellular DNA, can delay the penetration of several charged antibiotics through the biofilm (temporal heterogeneity). Through these barriers, bacteria may initially be exposed to a low antibiotic concentration, which gradually increases over time, allowing them to sense and develop defensive responses. To address this limitation, the encapsulation of antimicrobial agents in nanocarriers can protect them from binding to matrix material and enzymatic inactivation (Figure 2). As a result, a total dose of antimicrobial agents can be rapidly delivered to all cells inside the biofilm [33]. This approach has been widely reported in several studies and summarized in a recent review [4].

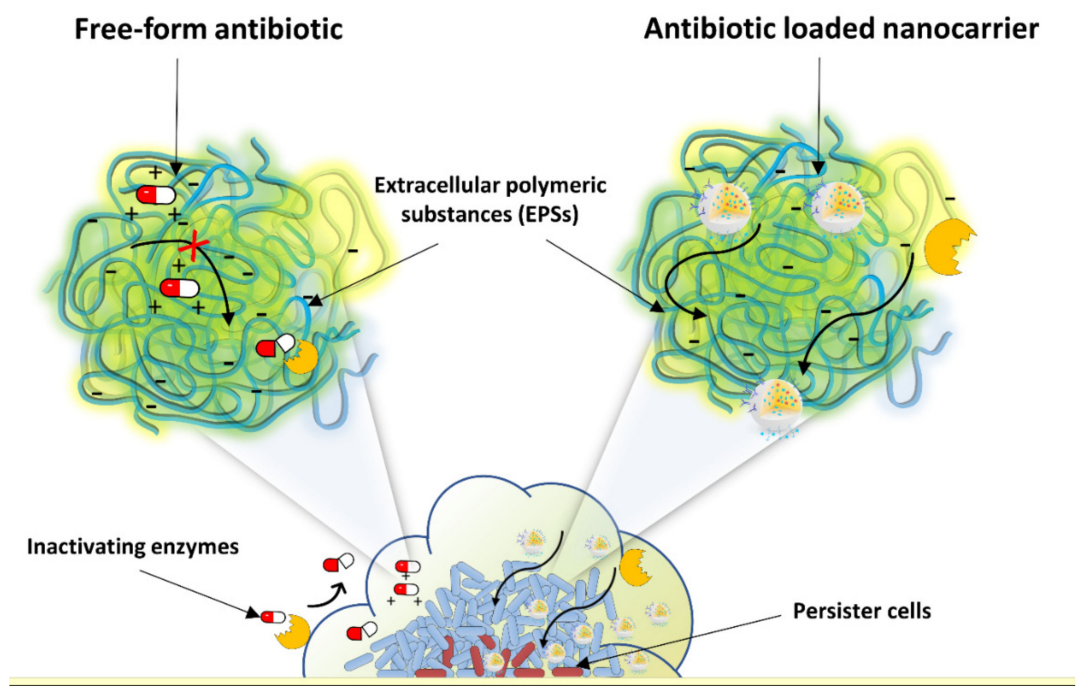

Figure 2. Schematic illustrates the protection mechanisms of antibiotic-loaded nanocarriers from deleterious interactions with the extracellular polymeric substances (EPS) or enzymatic inactivation in bacterial biofilm. 


\section{Controlled Antibiotic Delivery}

\subsection{Sustained Antibiotic Delivery}

The concept of a sustained-release formulation is a crucial aspect of antibiotic delivery [34]. In chronic infection treatment, a long course of sufficient antibiotic exposure is essential to ensure the eradication of the microorganism. However, maintaining the antibiotic concentrations within a therapeutic window (between the drug's maximum tolerated and lowest effective doses) is often difficult to achieve in conventional dosage forms. In addition, due to limited bioavailability, many antibiotics have a short half-life and need to be administered frequently, resulting in poor patient compliance.

In this regard, polymeric nanocarriers may serve as reservoirs to provide sustained antibiotic release profiles with a lower dosing frequency [35]. The sustainable antibiotic release from a polymeric matrix occurs via three main mechanisms: solute diffusion, polymeric matrix swelling or erosion/degradation, and loss of the antibiotic-polymer bond. These mechanisms may act simultaneously or independently at different stages of a delivery process, depending on the composition (polymer, drug, excipient), the ratio, physical or chemical interaction among components, particle size, and manufacturing methods [36,37]. This allows antibiotic concentrations at the site of infection to be maintained at the required effective levels for a prolonged period of time, maximizing the therapeutic effect while minimizing the adverse effects of antibiotics. Another undoubted advantage of the sustained-release nano-formulation is the improvement in patient compliance, as frequent administration can be reduced.

For example, in an attempt to overcome bacterial infections that occur at sites with high shear forces, such as infective endocarditis, corneal infection, and urinary tract infections, challenging effective antibiotic retention, Zhang et al. developed a bioadhesive NP-hydrogel hybrid to enhance localized antimicrobial drug delivery (Figure 3A) [38]. The combination of two distinct delivery platforms, PLGA NPs and hydrogel, allows the hydrogel network properties to be independently tailored for adhesion while maintaining sustained drug release kinetics from the NPs. The nanocarrier-based system showed superior antibiotic retention under high shear stress on biological surfaces, including a bacterial film, a mammalian cell monolayer, and mouse skin tissue. Similarly, another application of PLGA nano-formulations prolonged the concentration of antibiotics available in the precorneal area, providing a better curative effect than conventional antibiotic eye drops [39]. 

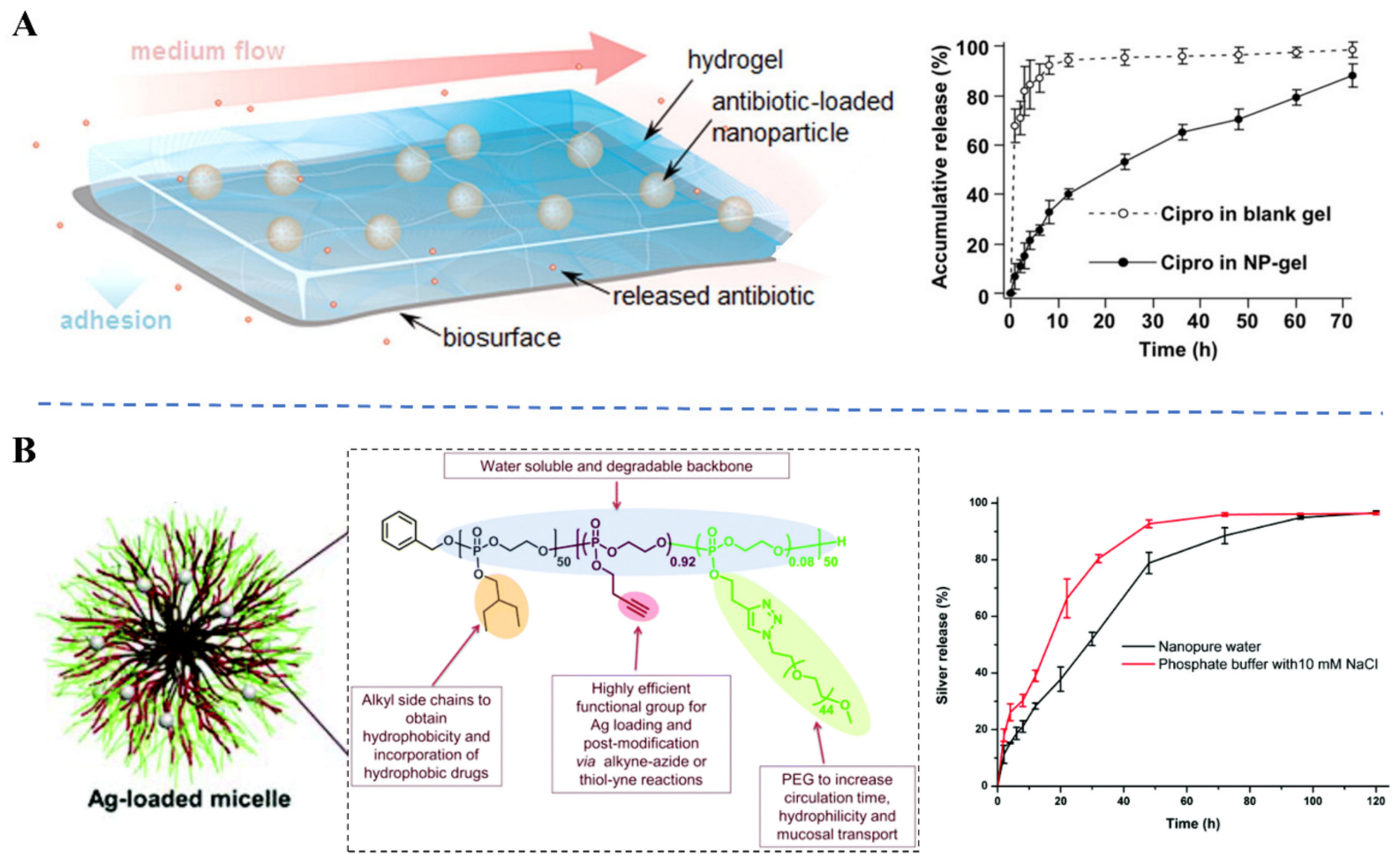

Figure 3. Examples of extended-release antimicrobial delivery systems based on polymeric nanocarriers. (A) (Left) Schematic illustration of tissue-adhesive nanoparticle-hydrogel hybrid (PLGA NP-gel) biomaterial system for sustained antibiotic release. (Right) The accumulative release profile of antibiotic Ciprofloxacin (Cipro) from Cipro-loaded PLGA NP-gel and Cipro-loaded blank gel without PLGA NPs in PBS buffer (adapted with permission from [38], copyright 2016 ACS). (B) (Left) Overall design of the degradable amphiphilic block terpolymer for assembly into NPs capable of silver-based antimicrobial delivery. (Right) Sustained-release profiles of silver cations from the NPs at $37^{\circ} \mathrm{C}$ in pure water and PBS buffer (reproduced with permission from [40], copyright 2015 Royal Society of Chemistry).

In order to improve patient compliance in tuberculosis chemotherapy, Sharma et al. developed an extended-release antibiotic delivery system based on PLGA NPs that allowed co-loading three first-line anti-tuberculosis (TB) drugs (isoniazid, rifampicin, and pyrazinamide) [41]. In vivo investigations revealed that three doses of oral/nebulized nano-formulation (fortnightly) could yield undetectable mycobacterial colony-forming units, an excellent preclinical outcome comparable to 45 doses of conventional oral drugs. In the same approach, by using a sustained-release nano-formulation for the treatment of intracellular Brucella infection, Lueth et al. demonstrated a seven-fold dose-sparing benefit when comparing the bacterial counts in the spleen and liver from mice treated with a weekly dose of antibiotic-loaded polyanhydride NPs and with the daily dose of the free drug [42].

Surprisingly, slow-release nano-formulations have also been widely used for unstable antimicrobials or those with many side effects to ensure therapeutic efficacy and minimize side effects. For example, loading of lysozyme in chitosan NPs effectively preserved the antibacterial activity of the loaded enzyme and showed a sustained drug release profile for 3 weeks in vitro [43]. In a study by Zhang et al., silver cation-loaded polyphosphoester NPs were developed as an effective and safe treatment for lung infections (Figure 3B) [40]. This dosage form maintained a continuous delivery of silver in a sustained manner over 5 days, which enhanced in vitro antibacterial activities against cystic fibrosis-associated pathogens (e.g., P. aeruginosa, S. aureus, Burkholderia sp.) and decreased cytotoxicity to human bronchial epithelial cells compared to silver acetate. 
An important consideration with new antibiotic dosage forms is the pharmacokineticpharmacodynamic relationship. Intriguingly, the sustained-release formulations potentially improve the therapeutic index of time-dependent antibiotics. For these agents, the time that therapeutic concentrations are above the minimum inhibitory concentration $(\mathrm{T}>\mathrm{MIC})$ is the primary parameter and should be kept for a minimum standard to achieve the desired clinical outcomes. By maintaining a constant plasma drug concentration over MIC for a prolonged period, extended-release dosage forms maximize the therapeutic effect of antibiotics while minimizing antibiotic resistance [34,44].

On the contrary, in cases of concentration-dependent antibiotics (depending on the peak concentration $\mathrm{C}_{\max } / \mathrm{MIC}$ ) or those with high toxicity, the administration of the sustained-release dosage form may not show a beneficial clinical outcome and perhaps even may show a risk of harm [45]. Indeed, premature antibiotic release from the nanocarrier before reaching the site of infection may lead to many adverse effects on normal tissues and on the microbiome. On the other hand, declining amounts of antibiotics released during the final stage of the release process result in the potential for prolonged sub-MIC concentrations at the site of action, thereby compromising the therapeutic efficacy of the system. To overcome these limitations, current nanocarrier-based delivery systems have been upgraded to a "smart" level, enabling a controlled drug release via specific stimuli in the infectious site. The triggers can involve physiological conditions in the target tissue (e.g., changes in $\mathrm{pH}$, the activity of certain enzymes, redox condition) or can also be external (e.g., light irradiation, ultrasound, magnetic field). Selecting the proper stimuli in different situations is the key to designing an effective antibiotic delivery system. However, it should be noted that this approach is complex, requiring biocompatible and highly flexible materials that can undergo structural or chemical modifications in response to these stimuli.

The following subsections will focus on recent developments in the design of stimuliresponsive nanocarrier systems for antibiotic delivery, including endogenous stimuli and exogenous stimuli.

\subsection{Endogenous Stimuli-Responsive Antibiotic Delivery}

Variations in microenvironment characteristics are the important marker for bacterial infections, making them attractive targets for designing stimuli-response delivery systems (summarized in Table 1). In this respect, antibiotic-loaded NPs can be synthesized or modified via various polymers or labile chemical bonds that respond to the specific stimuli to release the therapeutic cargo selectively.

Table 1. Differences in physiological parameters between normal and pathological tissues.

\begin{tabular}{ccc}
\hline Biological Parameters & Normal Tissues & Pathological Tissues \\
\hline $\mathrm{pH}$ & 7.4 & $\begin{array}{c}5-7.0 \text { in inflammatory tissue } \\
\text { 4.5-6.5 in endosomes and lysosomes } \\
\text { Acid-pH gradients in biofilm (4.5-6.5) }\end{array}$ \\
\hline Enzyme & Low expression & $\begin{array}{c}\text { Overexpression (Lipase, Protease) } \\
\text { Or specific enzyme expression } \\
\text { ( } \beta \text {-lactamase, elastase LasB) }\end{array}$ \\
\hline $\begin{array}{c}\text { Reduced glutathione (GSH) } \\
\text { (Reducing environment) }\end{array}$ & Low level & $\begin{array}{c}\text { High level in intracellular } \\
\text { environment of macrophages and } \\
\text { bacteria (2-10 mM) }\end{array}$ \\
\hline $\begin{array}{c}\text { Reactive oxygen species (ROS) } \\
\text { Nitric oxide (NO) }\end{array}$ & Low level & $\begin{array}{c}\text { High level in inflammatory } \\
\text { environment (Neutrophil production) } \\
\text { High level in biofilm }\end{array}$ \\
\hline Low level & $\begin{array}{c}\text { High level (Proinflammatory } \\
\text { mediator) }\end{array}$ \\
\hline
\end{tabular}


One of the most exploited stimuli in controlled-release antibiotic applications is $\mathbf{p H}$. Indeed, the $\mathrm{pH}$ value of pathological tissues subjected to inflammation is significantly different from healthy tissue. The anaerobic fermentation in some bacteria, in which the products are organic acids such as lactic and acetic acids, and the inflammation response cause the $\mathrm{pH}$ of the site of infection to be significantly lower (pH 5-7) than the healthy tissue ( $\mathrm{pH}$ 7.4). Based on this characteristic, many $\mathrm{pH}$-sensitive nano-antibiotic systems have been widely designed by incorporating the ionizable groups or acid-labile bonds (hydrazine, amide, and ester linkages) in their polymer matrix [46,47]. These systems retain their stability during the systemic circulation under normal physiological $\mathrm{pH}$ conditions ( $\mathrm{pH}$ 7.4) while collapsing in an acidic microenvironment, resulting in the release of the loaded antibiotic at the desired locations.

For instance, polymyxin B is an old antibiotic with excellent bactericidal activity against gram-negative "superbugs". Unfortunately, the high nephrotoxicity and neurotoxicity occurring during systemic polymyxin therapy strongly limited its clinical applications. To address this issue, Chai et al. reported a charge switchable polyion nanocomplex with a pH-sensitive property to improve polymyxin's biosafety while retaining its excellent antibacterial activity (Figure 4A) [48]. The nanocomplex was prepared through electrostatic interaction of positively charged polymyxin B and negatively charged 2,3-dimethyl maleic anhydride-grafted chitoligosaccharide. Upon arriving in infectious sites, the negative charge of the graft polymer will convert to positive due to the hydrolysis of amide bonds in the acidic environment, leading to the disassembly of the nanocomplex and release of polymyxin $B$. As a result, the toxicity of the nanocomplex dramatically decreased compared to free polymyxin B while exhibiting superior bactericidal activity against $P$. aeruginosa in an acute lung infection mouse model.

Likewise, in attempts to control cariogenic dental biofilms, a pH-sensitive diblock copolymer composed of 2-(dimethylamino)ethyl methacrylate (DMAEMA), butyl methacrylate (BMA), and 2-propylacrylic acid (PA) was synthesized to form cationic micellar drug carriers, capable of binding to the biofilm matrix (Figure 4B) [19]. Owing to hydrophobic cores, the micelle system allows the loading of hydrophobic antimicrobials and their release on demand at acidic $\mathrm{pH}$, characteristic of cariogenic biofilm microenvironments (through core destabilization). Topical treatment (twice daily) of the antibiotic-loaded micelles effectively attenuated biofilm virulence in a rodent dental caries disease model, while free antibiotic had no effect. 
A 1.
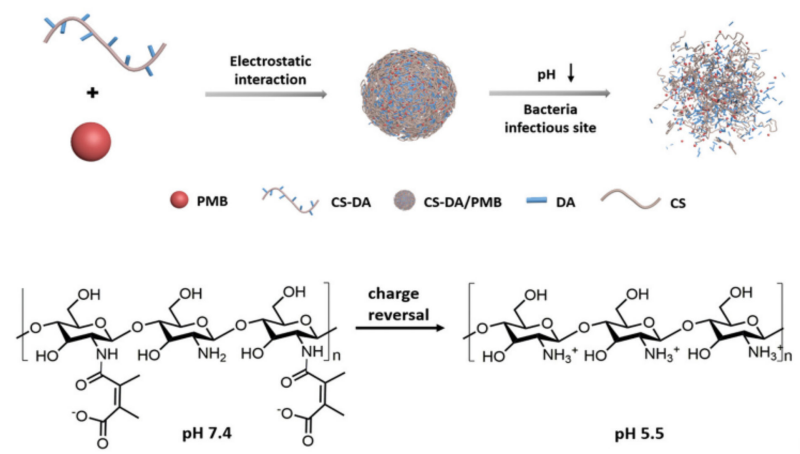

2. In vivo drug safety

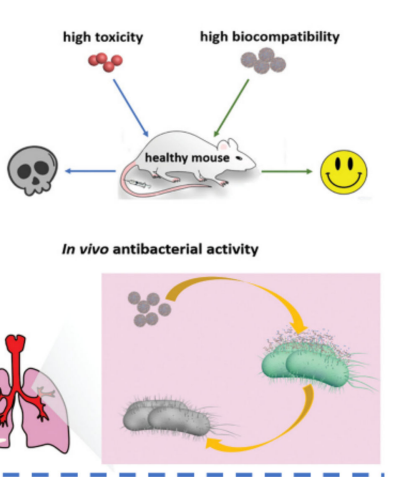

B
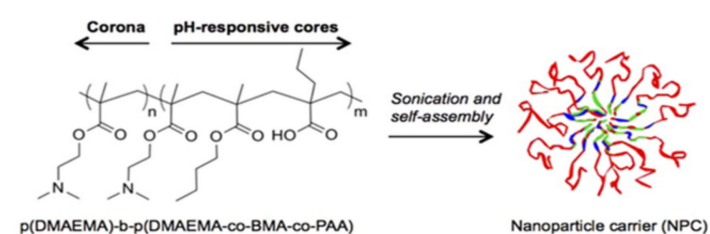

pH 7.2

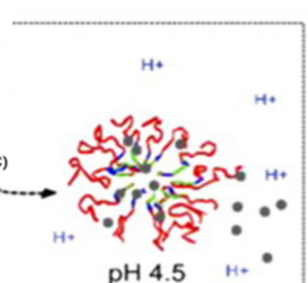

Rapid drug

release

pH 4.5

Acidic biofilm environment

$\mathrm{H+}$

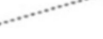

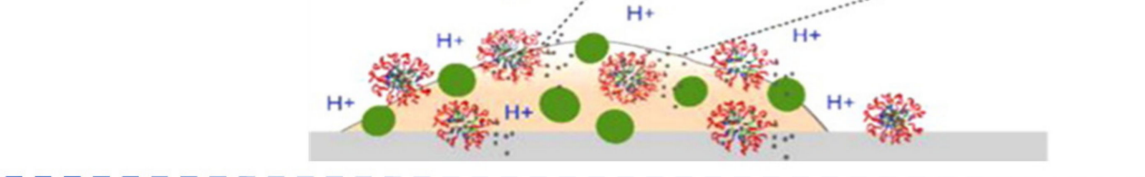

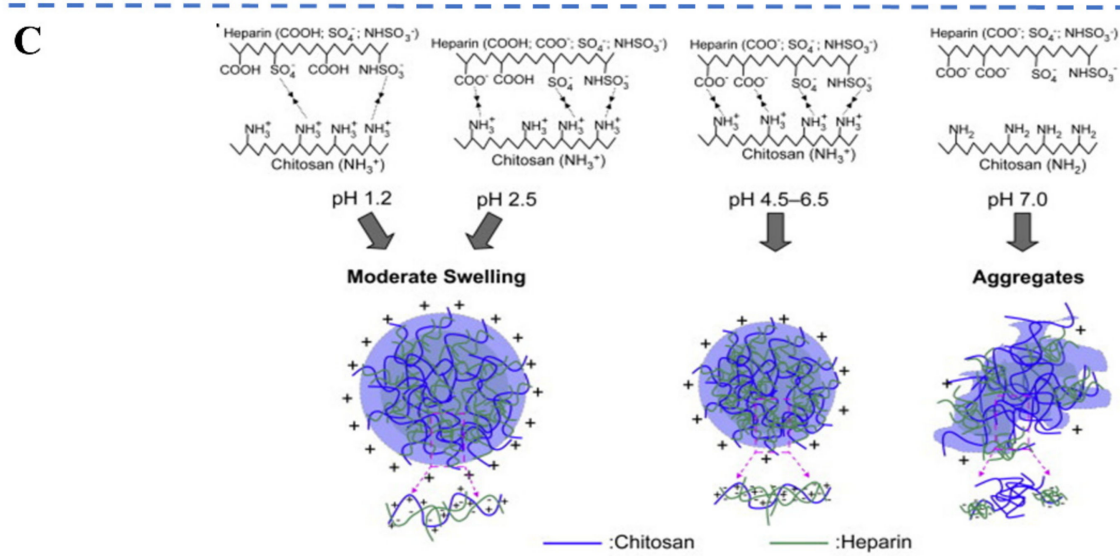

Figure 4. Examples of $\mathrm{pH}$-responsive nanocarriers for antibiotic delivery. (A) (1) Schematic illustration of a pH-sensitive polyion nanocomplex for delivery of Polymyxin B (PMB). The NPs were prepared through electrostatic interaction of positively charged PMB and negatively charged 2,3-dimethyl maleic anhydride (DA)-grafted chitoligosaccharide (CS). (2) Schematics of in vivo drug safety, different from free PMB and CS-DA/PMB, and the mechanism of antibacterial activity of CS-DA/PMB (reprinted with permission from [48], copyright 2020 John Wiley and Sons). (B) The self-assembly structure and mode of action of acidic $\mathrm{pH}$-sensitive micelles in delivering antibacterials in cariogenic dental biofilms (adapted with permission from (19), copyright 2015 ACS). (C) Illustrations of the physical structures of chitosan/heparin pH-sensitive NPs, an application in the treatment of H. pylori infection (reprinted with permission from [49], copyright 2009 Elsevier).

Alternatively, $\mathrm{pH}$-responsive behavior has also been used in the treatment of resistant intracellular infections, where bacteria are found in acidic intracellular compartments (endosomes pH 5-6 or lysosomes $\mathrm{pH} 4-5$ ). For instance, by encapsulating the hydrophilic antibiotic drug ceftazidime in a $\mathrm{pH}$-responsive polymersome system, Lane et al. demon- 
strated that antibiotics were effectively retained within the polymersomes until endosomal acidification caused spontaneous disassembly resulting in burst drug release as well as endosomal disruption [50]. Treatment with the ceftazidime-loaded polymersomes significantly reduced the number of intracellular Burkholderia thailandensis bacteria in RAW 264.7 cells compared to the free antibiotics (undetectable levels at $0.2 \mathrm{mg} \mathrm{mL}^{-1}$ loaded ceftazidime). Similarly, Lunn et al. recently described a novel formulation based on the mannosylated polymeric NPs, in which antibiotics were covalently linked via a pH-responsive hydrazone bond (poly(diacetone acrylamide-hydrazone-isoniazid)) [51]. This drug delivery agent exhibited an increased macrophage uptake and enabled the on-demand release of antibiotics upon exposure to the acidic phagolysosome. The in vitro treatment of these antibiotic-loaded NPs was shown to effectively kill intracellular mycobacteria, whose resistance mechanisms arise from the poor intracellular delivery of a range of antibiotics.

In contrast to the examples above, treatment of Helicobacter pylori gastric infections is a special case, which requires a dosage form with $\mathrm{pH}$-stimulated release in the opposite direction. H. pylori is a spiral microorganism and mainly resides in the gastric mucosa or at the interface with the mucus layer. It can secrete urease enzymes, hydrolyzing urea to ammonia and bicarbonate to neutralize the acidic $\mathrm{pH}$ around them. To successfully eliminate $H$. pylori infections, the oral antibiotic must have good stability in the gastric acid ( $\mathrm{pH} 1$ to 3 ) before reaching its target site, where the $\mathrm{pH}$ is close to 7.4 [52,53]. By taking advantage of this limitation, Lin et al. developed stable chitosan/heparin nanocarriers, allowing them to protect active compounds from destructive gastric acids (Figure 4C) [49]. In addition, the nanosystem could adhere to the gastric mucosa (thanks to the excellent mucoadhesive properties of chitosan), increasing the gastric residence time and infiltrating the mucus layer. However, upon contact with $H$. pylori in the gastric mucosa at neutral $\mathrm{pH}$, chitosan (pKa 6.5) is deprotonated, causing the collapse of the NPs and the release of antibiotics. Although no animal studies have yet been conducted to examine this hypothesis, the transformable biomaterials-based nanocarriers were expected to enable specific accumulation of antibiotics in the infectious site, resulting in an enhanced binding capability and killing efficacy toward H. pylori.

Likewise, the high expression level of microbial enzymes in the infectious site is another powerful trigger for antibiotic release. Most bacteria secrete specific enzymes into the environment to digest macromolecules as nutrients for growth and maintenance. In some cases, bacteria produce specific extracellular enzymes as a defense mechanism to break down toxic compounds in their surrounding environment, including antibiotics. By taking advantage of this property, many enzymes and their respective stimuli-responsive nanosystems for antibiotic delivery have been developed, as shown in Table 2. Broadly, the technical point of this design is based on the insertion of sensitive polymers or enzyme-cleavable chemical bonds into the nanocarrier matrix.

For example, Lipase is one of the most widely targeted enzymes in enzyme-responsive systems due to its particularly abundant presence at infection sites. By designing NPs based on polyphosphoester or phosphoester bonds, which can be readily degraded by bacterial lipases, many reported drug delivery nanosystems allowed for a precise release of antibiotics at the site of inflammation, eliminating undesirable side effects caused by premature antibiotic leakage [54-59].

In another example, Qi et al. developed an "on-site transformation" strategy to precisely deliver antibacterial agents in the presence of gelatinase secreted by bacteria (Figure 5A) [60]. The design is based on transformable polymer-peptide conjugates consisting of three elements, a chitosan backbone, an enzyme-cleavable peptide with a polyethylene glycol (PEG) terminal, and an antibacterial peptide. The conjugates were self-assembled into NPs and morphologically transformed into nanofibers in the presence of gelatinase, leading to the high exposure of antimicrobial peptide residues with bacterial membranes. Taking advantage of the in situ morphological transformation, this strategy offered various merits in terms of increasing binding, effective accumulation, prolonged retention at the bacterial infection environment, and enhanced antibacterial activity. 
A
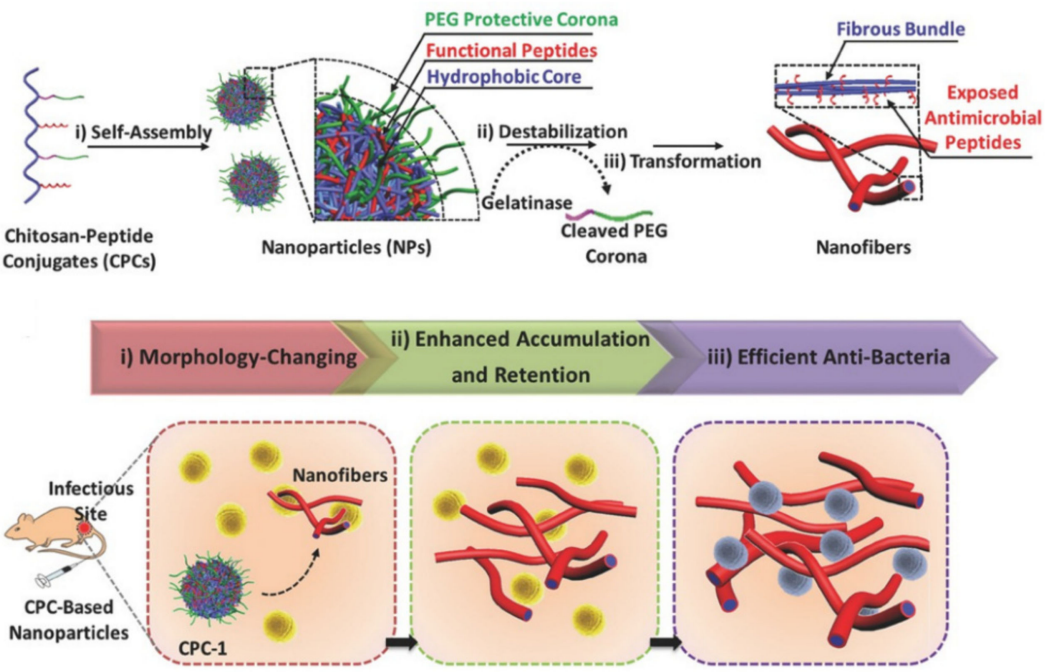

B

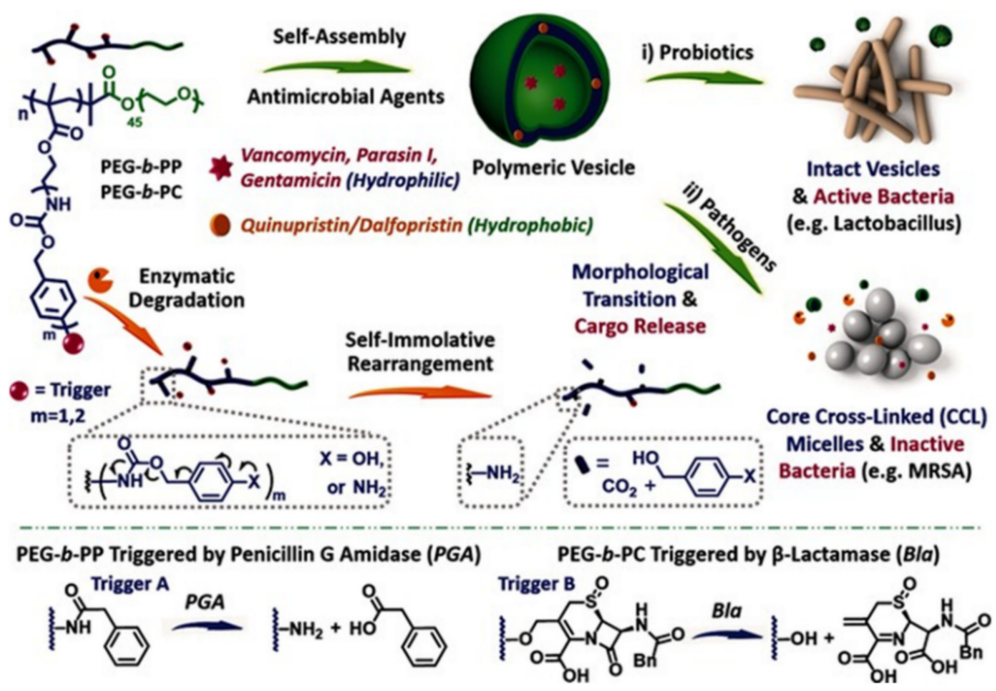

Figure 5. Examples of enzyme-responsive nanocarriers for antibiotic delivery. (A) Illustration of the self-assembly of polymer-peptide conjugate NPs and the principle of enzyme-induced morphology transformation with the high antibacterial ability (reprinted with permission from [60], copyright 2017 John Wiley and Sons). (B) Illustration of enzyme-responsive polymeric vesicles for bacterial strainselective delivery of antibiotics. Polymeric vesicles are self-assembled from synthesized polymers subjected to side-chain cleavage and microstructural transformation in response to penicillin $G$ amidase and $\beta$-lactamase. This process is accompanied by sustained release and bioactivity recovery of encapsulated antibiotics (reprinted with permission from [61], copyright 2016 WILEY-VCH Verlag $\mathrm{GmbH} \&$ Co. KGaA, Weinheim).

In the same design, the development of nanocarriers responsive to antibiotic-resistant enzymes is another innovative application in which the killing activity is only activated within antibiotic-resistant bacterial infections and by their enzymes. Liu et al. reported self-assembled polymeric vesicles from amphiphilic diblock copolymers that were susceptible to degradation by penicillin $\mathrm{G}$ amidase (PGA) and $\beta$-lactamase (Bla) (Figure 5B) [61]. During NPs' formation, different antimicrobial agents (with hydrophilic or lipophilic properties) could be loaded into either hydrophobic bilayers or aqueous interiors. These formulations showed selective antibiotic delivery to MRSA strain in vitro and enhanced wound healing in a murine model.

Similarly, considerable research has also focused on constructing systems in response to reduced glutathione in intracellular pathogen sites, nitric oxide, or reactive oxygen 
species (ROS) in inflammatory environments. These studies have highlighted the potential of antibiotic delivery triggered by endogenous factors (Table 2). The response of the drug delivery systems to these internal stimuli allows specific release of the antibiotic payload in the infected site. In this sense, antibiotics are able to reach bacterial cells without drug leakage in normal tissues, thus decreasing the development of resistance. However, the success of these systems is still limited under optimal laboratory conditions where pathological parameters are often not correlated with those found in humans (high variation in environmental factors).

Table 2. Examples of stimuli-responsive nanocarriers for antibiotic delivery.

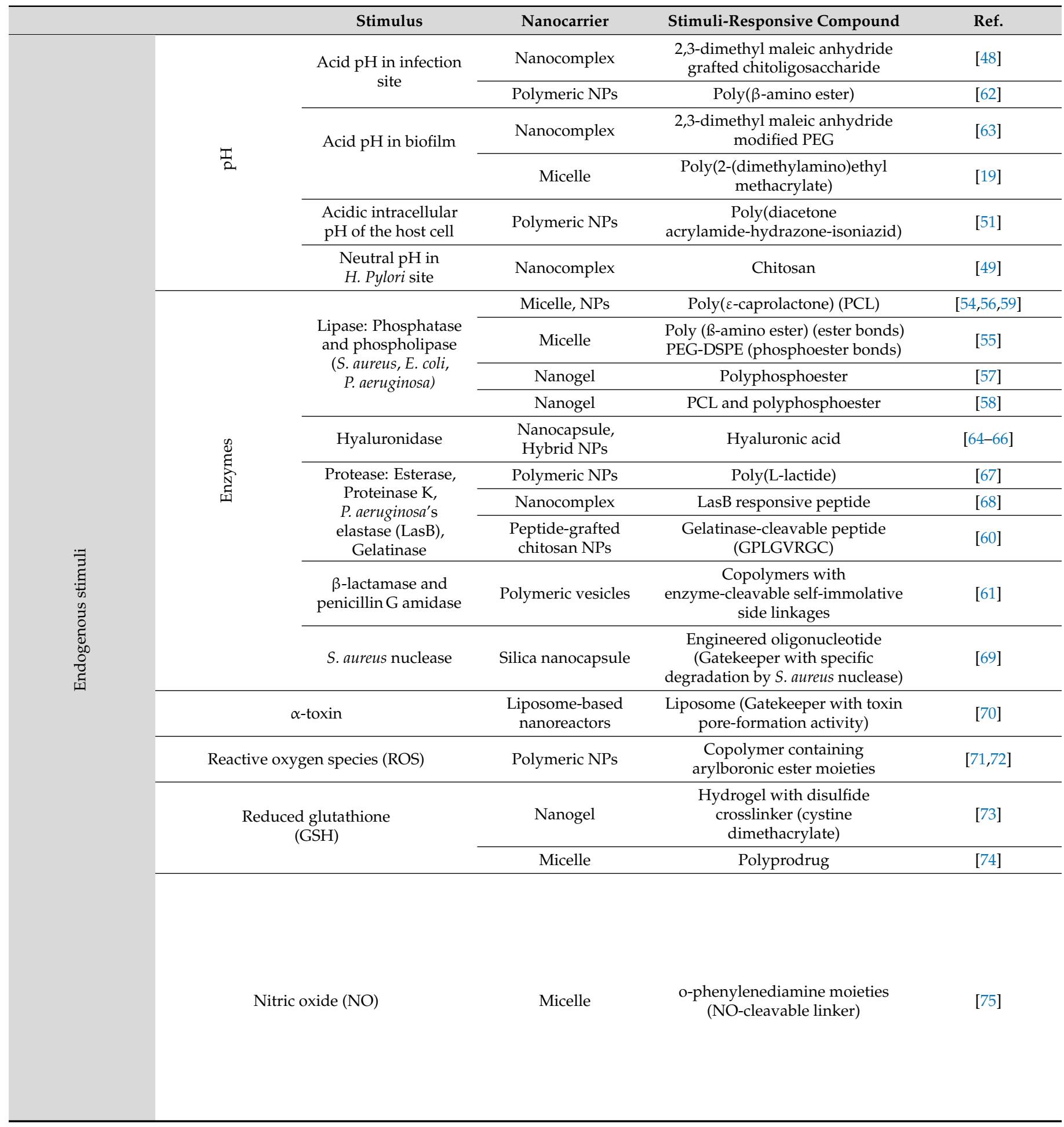


Table 2. Cont

\begin{tabular}{|c|c|c|c|c|}
\hline & Stimulus & Nanocarrier & Stimuli-Responsive Compound & Ref. \\
\hline \multirow{5}{*}{ 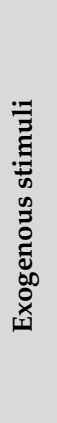 } & \multirow{2}{*}{$\begin{array}{l}\text { Light: Ultraviolet (UV), visible light, and } \\
\text { near-infrared (NIR) }\end{array}$} & Dendrimer & $\begin{array}{l}\text { Polymer-antibiotic conjugate via } \\
\text { photocleavable ortho-nitrobenzyl }\end{array}$ & [76] \\
\hline & & Polymeric NPs & Polydopamine, Polypyrrole & {$[77,78]$} \\
\hline & \multirow{2}{*}{ Ultrasound } & Polymeric NPs/MPs & $\begin{array}{l}\text { Polymer matrix } \\
\text { (alginate, PLGA) }\end{array}$ & [79] \\
\hline & & Hybrid NPs & $\begin{array}{l}\text { Complex Vancomycin-peptide } \\
\text { target sequence (-D-Ala-D-Ala) }\end{array}$ & [80] \\
\hline & Magnetic field & Polymeric NPs/MPs & Iron oxide NPs & [81-83] \\
\hline
\end{tabular}

\subsection{Exogenous Stimuli-Responsive Antibiotic Delivery}

Although endogenous stimuli enable the efficient triggering of antibiotic release, their low sensitivity and high biological variability from one individual to another may affect the clinical efficacy of these dosage forms. Hence, external stimuli can be recruited for additional specificity and sensitivity of the antibiotic delivery systems (Table 2). In the ideal case, there will be almost zero drug release until stimuli are applied. Further, compared to endogenous stimuli, the exogenous stimuli-responsive systems are much easier to spatially and temporally control. However, minimal damage to the surrounding healthy tissues and depth penetration of the treatment stimuli are two key factors determining this dosage form's success.

The light is among the most popular exogenous triggers for smart drug delivery systems due to its high biocompatibility, practicability, and precise control. Various lightresponsive nano-systems utilizing ultraviolet (UV), visible light, and near-infrared (NIR) have been intensively applied for on-demand antibiotic release [76-78,84]. In addition, light therapies such as photothermal and photodynamic therapy are currently used clinically as alternative treatment strategies to antibiotics [85]. Light-triggerable delivery systems can be achieved through different mechanisms, such as light-induced isomerization, bond cleavage, and disaggregation of carrier materials. The tissue penetration depth is the major obstacle of light-triggered delivery systems. While UV or visible light-trigger can only be applied to regions directly illuminated (penetration depth through the tissue less than $1 \mathrm{~mm}$ ), such as the skin and the eye, NIR lasers offer deeper tissue penetration (1-3 mm), lower scattering properties and with minimal photodamage. For example, Gao et al. recently reported an injectable hydrogel composed of glycol chitosan and ciprofloxacinloaded polydopamine NPs (Gel-Cip) as an on-demand antibiotic delivery platform under NIR light irradiation (Figure 6A) [77]. On the one hand, polydopamine NPs could efficiently convert NIR light into heat, indicating their excellent photothermal. On the other hand, the aromatic rings on the surface of polydopamine NPs enabled the adsorption of ciprofloxacin via $\pi-\pi$ stacking interactions, which could then be released upon NIR light irradiation. Taken together, these two effects acted in a synergistic way to eliminate bacteria more effectively and inhibited persistent $S$. aureus-induced infections in a mouse model and mouse skin defect model.

Similar to light, the ultrasound-triggered drug delivery system is also of particular interest for local on-demand delivery of antimicrobials. One main advantage of ultrasound is that it allows depositing high levels of energy on a small region of diseased tissue without harming the surrounding tissue [86]. Concurrently, ultrasound is well known as a potential combination therapy with antibiotics to increase antimicrobial efficacy (e.g., synergistic effects, biofilm degradation) [87]. 
By modulating the frequency and duty cycles, ultrasound can destroy the structure of nanocarriers and cause drug leakage through the thermal effects (high-frequency), radiation forces, and mechanical effects (low frequency). In a study by the Gu group, laser-generated focused ultrasound (LGFU) was effectively used to promote antibiotic release from a formulation comprised of alginate sphere microgels integrated with ciprofloxacin-loaded PLGA NPs [79]. Once the LGFU excites the microgels, cavitation effects at the microgels and oscillation of the microgels' shells promote the release of the drug from PLGA NPs and temporarily storing it in the microgels. Using a standard disk diffusion test, the resulting formulation exhibited superior antibacterial activities against $E$. coli after LGFU treatment, with significantly larger inhibition zone sizes than that without LGFU treatment.

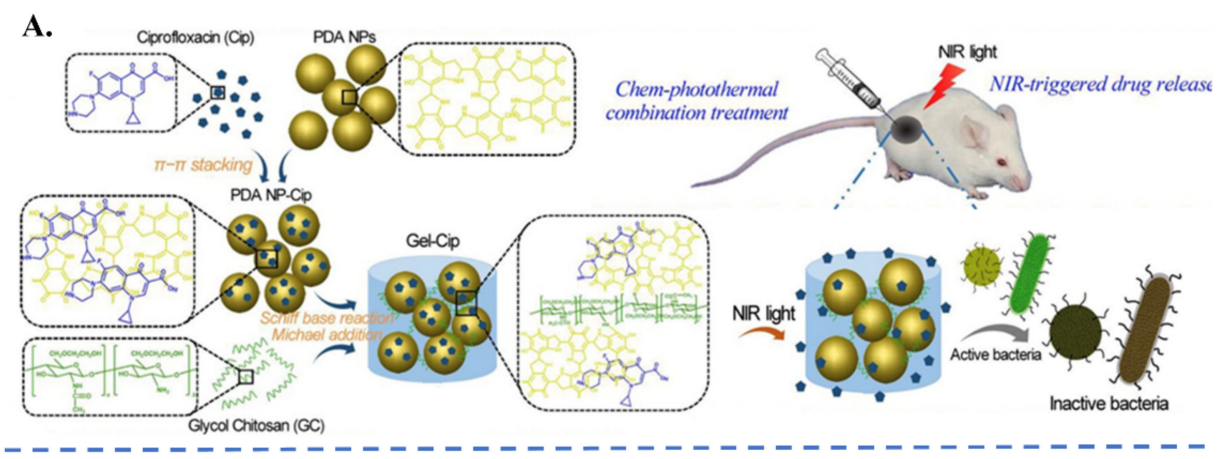

B.

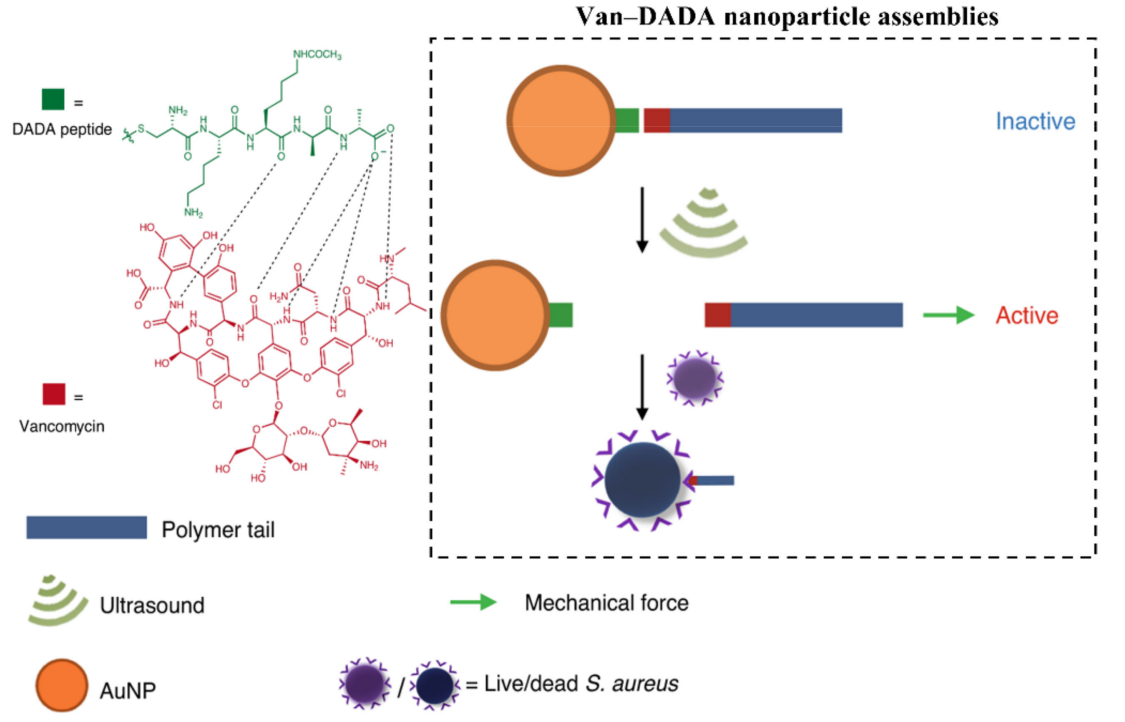

Figure 6. Examples of exogenous stimuli-responsive nanocarriers for antibiotic delivery. (A) Schematics of the synthetic route of a NIR-controllable on-demand antibiotics' release system using polydopamine nanoparticles (PDA NPs) for bacterial inactivation (reprinted with permission from [77], copyright 2019 Elsevier). (B) Schematic depiction of ultrasound activation of antibiotic assembled nanosystem. Van-DADA peptide assemblies activate the antibiotic properties of vancomycin to kill bacteria by ultrasound (adapted with permission from [80], copyright 2021 Springer Nature).

In another approach, ultrasound can be employed to destroy the non-covalent interactions (such as hydrogen bonds), leading to the activation of drugs from inactive macromolecules (Figure 6B) [80]. Inspired by the weak supramolecular binding between vancomycin with its $\mathrm{H}$-bond complementary peptide target sequence (peptide-D-AlaD-Ala), an ultrasound-triggered drug delivery system was fabricated by incorporating this supramolecular motif between polymer chains and gold NPs. Ultrasound applied in situ in the presence of S. aureus successfully lowered the MIC values of the formulations, highlighting the efficient supramolecular bond scission and activation of polymerterminated vancomycin. 
In the same way, magnetic fields have also recently been exploited as a trigger for cargo molecule delivery. A wide range of on-demand drug delivery systems has been developed by encapsulating magnetic NPs and antibiotics into the polymer nanocarrier matrix [81-83]. Antibiotics can be released from the system through two main mechanisms, mechanical force and thermal effect under a magnetic field. These organic/inorganic hybrid nanosystems appear to be a promising new weapon for eradicating persistent bacteria in biofilms. However, challenges related to the potential toxicity and the metabolic fate of magnetic NPs need to be addressed to induce active development and applications of the antibiotic delivery formulation.

\section{Targeted Delivery of Antibiotics to Sites of Infection}

Compared with controlled drug delivery, the selective delivery of the antimicrobials to the infected site is an equally important function of an effective nanocarrier. Indeed, systemic administration of antibiotics is the preferred regimen in the treatment of most infectious diseases. However, the uniform distribution throughout the entire body results in only a small fraction of the antibiotic reaching the site of infection, especially in poorly irrigated areas. The subtherapeutic antibiotic concentration is known to exacerbate infectious complications further and promote antibiotic resistance. Indeed, resistance is mainly acquired by the stepwise accumulation of mostly low-effect mutations that occur in low-antibiotic concentrations.

In this context, the administration of targeting drug-loaded nanocarriers is one of the promising solutions to alter the tissue distribution and plasma pharmacokinetics of the antibiotics. After administration into the systemic circulation, nanocarriers will reach the infected sites through passive and/or active targeting mechanisms (Figure 7). In passive targeting, the nanocarriers use their intrinsic properties to achieve better accumulation at the site of infection, known as the enhanced permeability and retention effect (EPR effect) [88]. Subsequently, active targeting is applied based on the affinity of the ligand on the nanocarrier surface toward the receptors that are highly expressed on bacterial cells or infected tissue. Broadly, by adjusting the characteristics, such as size, shape, and surface coating, targeting nanocarriers could provide a higher concentration of antibiotics at the site of infection while maintaining standard dosing frequency [89]. The high-dose exposure of antibiotics to bacterial cells could overload the defenses of drug-resistant bacteria. At the same time, the lower dose at normal tissues minimizes off-target effects such as toxicity or the emergence of reservoirs of microbial resistance genes in commensal bacteria.

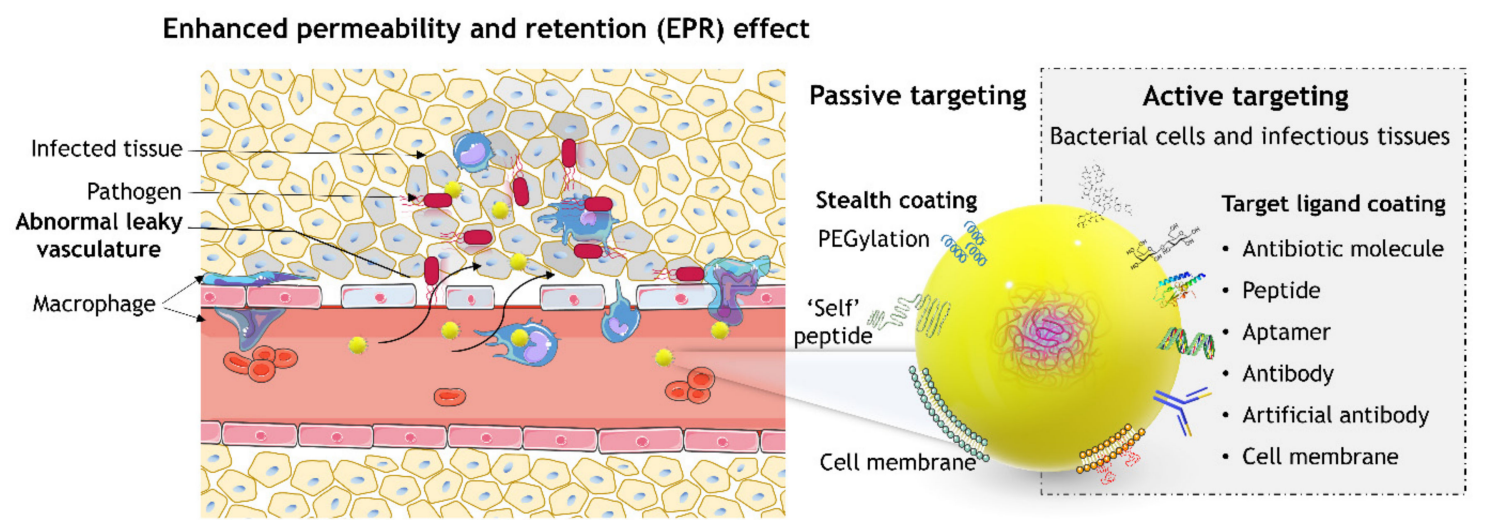

Figure 7. Schematic representation of antibiotic-loaded nanocarriers that passively or actively target infection sites. Both types of nanocarriers firstly reach infection sites through the enhanced permeability retention (EPR) effect caused by infection-induced inflammation (passive targeting). Surface coating strategies have been used to camouflage NPs, preventing opsonization and sequestration by the MPS system for prolonged circulation (stealth coating). Active targeting is then mediated by selective binding between ligand-coated nanocarriers and receptors overexpressed or uniquely expressed by target infection sites. 


\subsection{Passive Targeting: Enhanced Permeability and Retention Effect}

The enhanced permeability and retention (EPR) effect is the property through which macromolecules can extravasate and accumulate in injured areas such as inflammation, infection, infarcts, and especially in the tumor-vascularized area (angiogenic switch) [89-91]. The common feature of these lesions is frequently associated with abnormalities of the blood vasculatures, including the formation of an inter-endothelial cell gap (increasing vascular permeability) and dysfunctional lymphatic drainage (decreasing the efflux of macromolecules). In addition, bacterial components are also known to activate various inflammatory mediators that directly stimulate vascular permeability in the infection site [88]. Through this "passive" targeting mechanism, nanocarriers with prolonged blood circulation time have a better chance to accumulate at the infectious site, thereby enhancing antibiotic bioavailability (Figure 7). As a result, a higher antibiotic concentration to the site of interest would be obtained while reducing damage to surrounding tissues, which cannot be achieved by systemic administration of the free-form antibiotic.

Although this is not a new concept, the clinical application of the EPR effect in drug nanocarrier delivery systems is still challenged, and there is always room for improvement. Indeed, besides the EPR effect, NPs are subjected to opsonization processes (protein corona formation) and rapid uptake by the mononuclear phagocyte system (MPS) or reticuloendothelial system (RES) in the liver and the spleen, resulting in their rapid elimination from the bloodstream. These undesirable interactions are closely related to the physicochemical properties of the nano-systems, such as particle size, shape (chemical structure), surface charge, and surface coating. Subtle changes in these parameters may significantly affect the transport behavior of nanocarriers in the human body. In this regard, the main focus of the researchers is to develop strategies that allow limiting the opsonization and sequestration by the MPS/RES, thereby prolonging the circulation time of the nanocarriers in blood vessels.

It must be noted that the accumulation of NPs in macrophages makes them potentially useful for the treatment of intracellular infections [92]. As a result, these targeting systems do not necessarily possess a prolonged circulation time in blood flow to ensure the efficient uptake of infected macrophages. In contrast, in the treatment of bacterial infections located outside the MPS, passive targeting requires nanocarrier systems exhibiting a longer circulation half-life to allow a sufficient amount of antibiotic cargos to reach the target area.

Several strategies have been used to protect NPs from the natural defense system of the body via manipulating the physicochemical characteristics of NPs. Among them, modifying the NPs' surface is the most frequently used method since surface properties play a crucial role in protein adsorption and interaction with host defense. For example, grafting of PEG to the surface provided a hydrating layer that hindered the formation of a protein corona [93], while the coating of NPs with host cell membranes (e.g., red blood cells) or 'self' peptide (mimicking the process of recognition of host cells in vivo, e.g., CD47) provided a biomimetic surface as active stealth strategy to the host's defenses (Figure 7) [94].

However, like other drug dosage forms, any substantial adjustments in their properties may cause undesirable changes in their stability or interaction with biological systems. Therefore, to ensure maximal targeting efficiency, NPs' characteristics should be optimized for each drug delivery purpose. For example, NP-surface PEGylation with a neutral charge is widely used to reduce nonspecific interactions, leading to prolonged circulation. However, the neutral surface lacks the significant bacterial binding ability, limiting the antibiotic delivery efficacy of these systems [95]. To address this issue, Chu et al. developed a charge-adaptive nanocarrier, based on triblock polymers PEG, PCL, and poly $(\beta$-amino ester) (PAE), which can quickly realize acidity-sensitive charge alterations and extend antibiotic delivery (Figure 8) [62]. Basically, given the $\mathrm{pH}$-dependent charge conversion characteristic of PAE (pKa 6.7), a nanocarrier holds a negative charge and a hydrophilic PEG shell at physiologic $\mathrm{pH} 7.4$, which are helpful for prolonged circulation. However, under acidic conditions at the infectious site, the nanocarrier gradually became positively charged 
due to the protonation of PAE, facilitating interactions with the negatively charged elements of the bacterial cell wall. In addition, the hydrophilic conversion of PAE also allowed a higher antibiotic release at the infectious site (endogenous-stimuli release), contributing to effective antibacterial therapy, as demonstrated in an infected subcutaneous model.

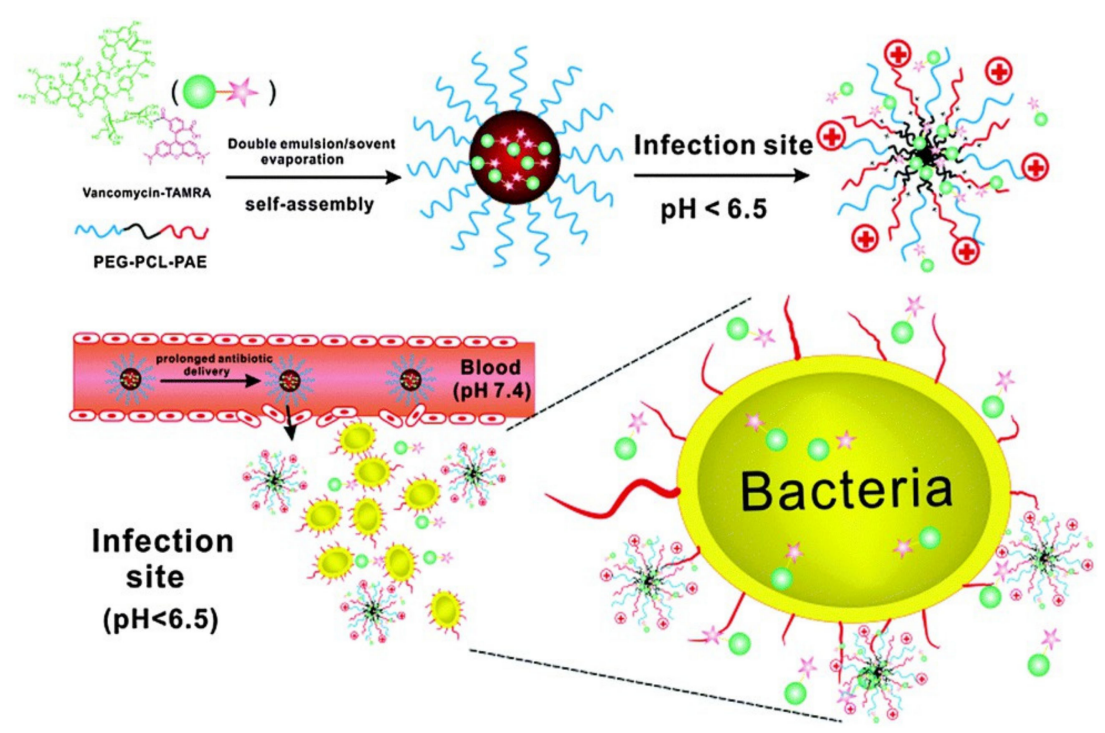

Figure 8. Schematic illustration of a charge-adaptive nano-system for prolonged and enhanced in vivo antibiotic delivery. These nanocarriers are designed to shield unspecific interactions during circulation at $\mathrm{pH} 7.4$ but bind avidly to bacteria in acidity, enhancing antibiotic delivery (reproduced with permission from [62], copyright 2016 Royal Society of Chemistry).

\subsection{Active Targeting}

In order to maximize the potential for infection-specific targeting, nanocarriers are conjugated to targeting agents, namely, ligands, that specifically bind to overexpressed receptors on the target site. These receptors are poorly or not even expressed on normal cells (healthy tissue or microbiome) but homogeneously present on bacterial pathogens or infectious tissues. These bindings allow antibiotic-loaded nanocarriers to be retained longer close to the infection site, overcoming fast clearance issues through the lymphatic drainages associated with small-molecule antibiotic treatment.

In this regard, identifying target molecules and designing nanocarriers are the key factors in applying active targeting drug delivery systems. Several ligands that target bacterial cells and infectious tissues are described in the following section and summarized in Table 3.

It is worth noting that nanocarriers must first reach the target area via the EPR effect (passive targeting) before ligand-receptor interaction with target cells (active targeting) occurs. Therefore, the design of actively targeting nanocarriers should always be accompanied by optimizing the factors associated with passive targeting. 
Table 3. Receptors and corresponding ligands for active targeting of antibiotic delivery systems.

\begin{tabular}{|c|c|c|c|}
\hline & Specific Ligand & Target Receptor & Target \\
\hline \multirow{7}{*}{ 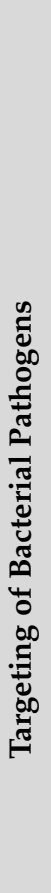 } & $\begin{array}{c}\text { Antibiotic molecules: Vancomycin [54,96] } \\
\text { Polymyxin B [97], } \\
\text { Daptomycin [98], } \\
\text { Ubiquicidin } \mathrm{UBI}_{29-41}[99]\end{array}$ & $\begin{array}{l}\text { Antibiotic biding sites: } \\
\text { D-Alanyl-D-alanine, } \\
\text { Lipopolysaccharide }\end{array}$ & $\begin{array}{l}\text { S. aureus, E. coli, } \\
\text { P. aeruginosa }\end{array}$ \\
\hline & $\begin{array}{c}\text { Carbohydrates: Glucopyranoside [100], } \\
\text { Galactose [101], Fucose [102], Dextran [103] }\end{array}$ & $\begin{array}{l}\text { Lectin: Concanavalin A, Lec } \\
\text { A, Lec B }\end{array}$ & $\begin{array}{l}\text { P. aeruginosa, E. coli, S. } \\
\text { epidermidis, S. aureus }\end{array}$ \\
\hline & $\begin{array}{l}\text { Aptamer oligonucleotide SA20 hp [104], } \\
\text { identified via SELEX procedure }\end{array}$ & Not determined & S. aureus \\
\hline & $\begin{array}{l}\text { Cyclic 9-amino-acid peptide CARG [105], } \\
\text { identified via phage display in vivo }\end{array}$ & Not determined & S. aureus \\
\hline & $\begin{array}{c}\text { Antibodies: Anti protein A [33], Anti } \\
\alpha \text {-toxin antibody [106] }\end{array}$ & $\begin{array}{l}\text { Protein A, } \\
\alpha \text {-toxin }\end{array}$ & S. aureus \\
\hline & $\begin{array}{l}\text { Artificial antibodies [107], identified via } \\
\text { molecular imprinting }\end{array}$ & Lipopolysaccharides & P. aeruginosa \\
\hline & $\begin{array}{c}\text { Cell membranes: Platelet [108], } \\
\text { Macrophage [109], Gastric epithelial } \\
\text { cell [110] }\end{array}$ & $\begin{array}{l}\text { Adhesin proteins } \\
\text { Lipoproteins, RNA, } \\
\text { Lipopolysaccharide }\end{array}$ & $\begin{array}{l}\text { H. pylori, } \\
\text { S. aureus, E. coli }\end{array}$ \\
\hline \multirow{7}{*}{ 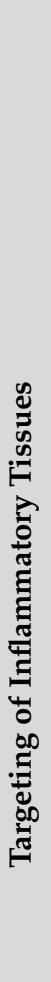 } & $\begin{array}{c}\text { Neutrophil-membrane (integrin } \beta 2) \text { [111,112] } \\
\gamma 3 \text { peptide (NNQKIVNLKEKVAQLEA) [113] } \\
\text { Anti-ICAM-1 antibody [55] }\end{array}$ & $\begin{array}{l}\text { Intercellular adhesion } \\
\text { molecule-1 (ICAM-1) }\end{array}$ & Inflamed vasculature \\
\hline & Bovine serum albumin [114]) & $\begin{array}{c}\text { Fc } \gamma \text { receptors on activated } \\
\text { neutrophil }\end{array}$ & $\begin{array}{l}\text { Inflamed tissues via neutrophil } \\
\text { hitchhiking }\end{array}$ \\
\hline & Erythrocyte membrane [73]) & Bacterial toxins & $\begin{array}{c}\text { Immune cells in presence of } \\
\text { bacterial toxins }\end{array}$ \\
\hline & $\begin{array}{l}\text { Carbohydrates: Mannose [57], } \\
\text { Curdlan (a linear } \beta-1,3 \text { glucan) [115], } \\
\text { Hyaluronic acid [75], Dextran [103] }\end{array}$ & $\begin{array}{l}\text { Mannose receptor, } \\
\text { Dectin- } 1 \text { receptor, } \\
\text { CD44 }\end{array}$ & $\begin{array}{c}\text { Infected macrophages, Infection } \\
\text { sites via macrophage } \\
\text { hitchhiking }\end{array}$ \\
\hline & S. aureus extracellular vesicles [116] & $\begin{array}{l}\text { Toll-like receptors on infected } \\
\text { macrophage } \\
\text { (trained innate immunity) }\end{array}$ & S. aureus-infected macrophage \\
\hline & Bacterial invasion proteins InvA497 $[117,118]$ & $\beta 1$-integrin receptors & $\begin{array}{c}\text { Inflamed cells } \\
\text { (caused by Yersinia, Salmonella } \\
\text { species) }\end{array}$ \\
\hline & Folic acid [119] & $\begin{array}{l}\text { Folate receptors on } \\
\text { infected cells }\end{array}$ & Chlamydia-infected tissues \\
\hline
\end{tabular}




\subsubsection{Active Targeting to Bacterial Cells}

There are huge differences between pathogenic and host cells, especially their surfaces, providing an "Achilles' heel" to recognize bacterial pathogens. Several ligands have been employed to functionalize NPs in active-targeting strategies, including antibiotic molecules, carbohydrates, aptamers, peptides, antibodies, and cell membranes (Table 3).

By linking these ligands to the surface of NPs, the antibiotic delivery systems can selectively bind to pathogenic microorganisms and release antimicrobials to kill or inhibit their growth, significantly improving the therapeutic efficacy of existing antimicrobial treatments.

Many types of antibiotics exert their effects by targeting the cell wall or cell membrane of bacteria. By taking these available facilities, the antimicrobial agents can be used at low doses as target molecules, offering great potential for applying targeted antibiotic delivery. For example, vancomycin acts by binding to the D-Ala-D-Ala fractions of the peptide subunits on the cell wall of Gram-positive bacteria, and, in a few cases, to the inner membrane of Gram-negative bacteria having an abnormal outer membrane. Therefore, the conjugation of vancomycin on the surface of NPs was proposed in various types of antibiotic-loaded nanoplatforms to target pathogenic bacteria. Figure $9 \mathrm{~A}$ is an illustrative example of a targeting micellar nanocarrier strategy via the antibiotic moieties [54]. The micelles could target bacterial walls using a vancomycin shell, which was then removed from the micelles via cleavage of hydrazone bonds under the acidic conditions surrounding the bacteria. Subsequently, the poly( $\varepsilon$-caprolactone) core was degraded by lipase overexpressed at the site of infection, releasing the encapsulated ciprofloxacin. The potential synergy between three "smart" concepts (active targeting, $\mathrm{pH}$, and enzyme-triggered drug release) and the antibiotic combination (ciprofloxacin and vancomycin) resulted significantly in increased antibacterial efficacy of the system. The micelle administration significantly improved the survival of $P$. aeruginosa-infected mice, reduced the bacterial burdens, and promoted the recovery of alveolar lesions in the lungs, compared with free drugs and micelles without ligand moieties.

Likewise, antibodies are one of the other potential ligands used in the active-targeting strategy. Antibodies play an important role in the immune system through multiple mechanisms. For bacterial infections, the $\mathrm{F}_{\mathrm{ab}}$ region (antigen-binding fragment) of the antibody can bind specifically to antigens of the bacterium, resulting in neutralization of the pathogen and prevention of infection. Due to their high selectivity, antibodies have been used in several diagnostic or therapeutic applications for infections. For example, recently exploited antibody-antibiotic conjugates (AACs) have shown to be more effective than conventional antibiotics in treating some infections [120]. In a similar approach, our group has also developed an antibody-conjugated nanocarrier system that effectively delivers antimicrobial drugs to bacterial biofilm (Figure 9B) [33]. The targeting nanocarriers were prepared by the nanoprecipitation method using biocompatible polymers that allowed for the encapsulation of a variety of antimicrobial molecules. This is an important advantage because constantly developed antibacterial agents can easily be administrated in the targeting dosage form. A single intravenous administration of the antibiotic-loaded targeted NPs significantly enhanced bactericidal activity against $S$. aureus biofilm compared to the free-form antibiotic and non-targeting NPs, as demonstrated in a mouse infection model. 
A.

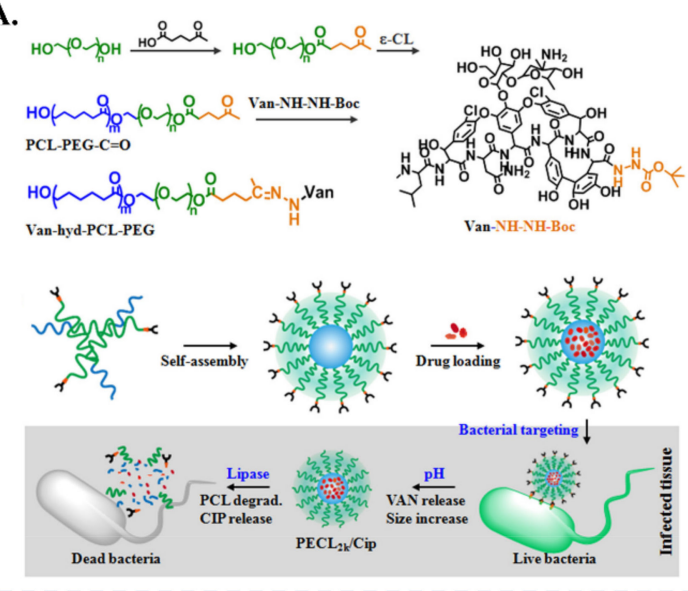

B.

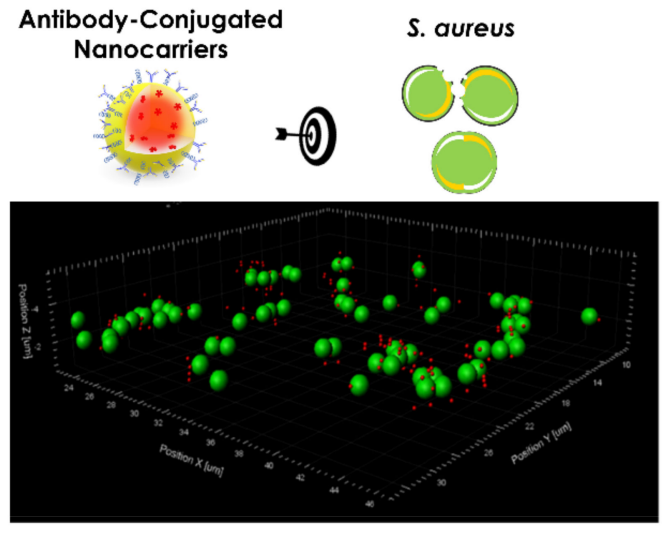

C.

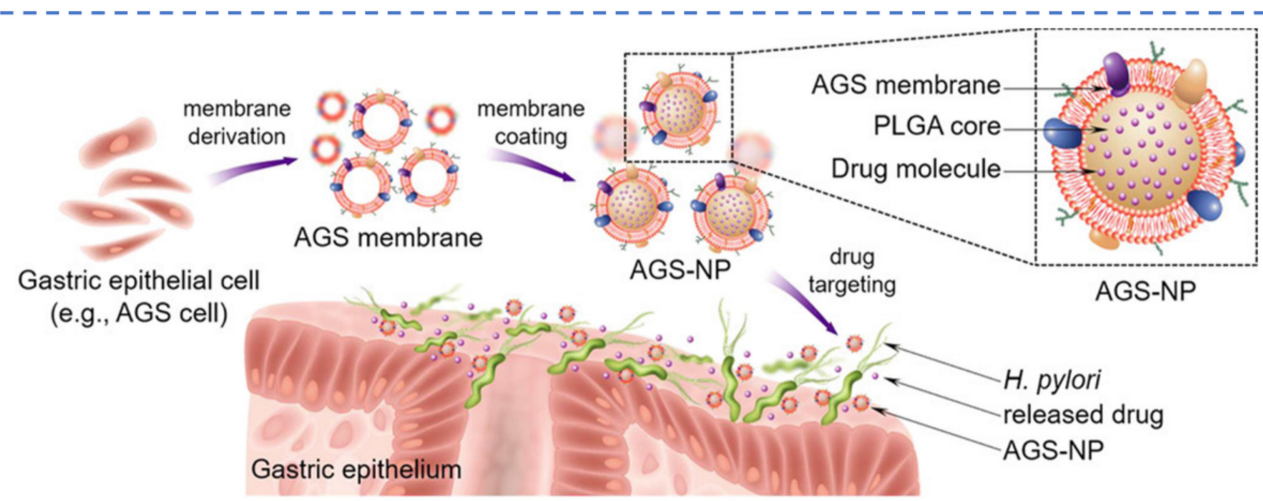

Figure 9. Active targeting of antibiotic-loaded nanocarriers to bacterial cells. (A) Schematic illustrations of formation, bacterial targeting, and drug release from micelles with vancomycin-mediated targeting (reprinted with permission from [54], copyright 2018 ACS). (B) Schematic illustrations of antibody-conjugated nanocarriers for targeted antibiotic delivery, and 3D fluorescent image showing a specific interaction between targeted NPs (red sphere) and S. aureus (green sphere) (adapted with permission from [33], copyright 2021 ACS). (C) Schematic illustrations of the application of gastric epithelial cell membrane-coated NPs for targeted antibiotic delivery to treat H. pylori infection (reprinted with permission from [110], copyright 2018 John Wiley and Sons).

In another approach, the host cell membrane is also employed to decorate the surface of nanocarriers as active targeting. Indeed, as one of the most fundamental biological units, cells are responsible for performing many functions necessary for life. Each cell type can be adapted and fully specialized for its own features. For example, while red blood cells are responsible for circulating and supplying oxygen, platelets play a central role in maintaining hemostasis and adhering to many foreign substrates, such as infectious diseases. By exploiting these available features and their natural functions, researchers have used different derivatives or entire cell membranes to target specific cells and tissues (Table 3) [108].

For example, H. pylori is shown to bind with integrin $\beta 1$ (CD29) and a group of carbohydrate receptors (such as mannose or fucose) in gastric epithelial cells (AGS cells). Inspired by this natural pathogen-host interaction, whole membranes of AGS cells were coated onto antibiotic-loaded polymeric cores, in a study by Angsantikul et al. [110]. The resulting biomimetic NPs bore the same surface antigens as the source AGS cells and, thus, had inherent adhesion to H. pylori (Figure 9C). Superior therapeutic efficacy of the antibiotic-loaded NPs has been demonstrated both in vitro and in a mouse model infection when compared with the free antibiotic as well as the non-targeted counterparts. Similarly, macrophage or platelet-coated nanocarrier systems are typical examples of this potential dosage form [108,109]. 


\subsubsection{Active Targeting to Infectious Microenvironments}

The infectious microenvironments are characterized by the overexpression of several factors such as bacterial toxins, inflammatory mediators, and recruited immune cells for bacterial clearance. Similar to the idea of endogenous drug delivery systems, many interesting targeting ligands of infectious microenvironments have been designed for coating nanocarriers.

For example, inflammatory activation of the endothelium triggers the production or upregulation of several molecules, promoting leukocyte recruitment. Among them, intercellular adhesion molecules (CAMs) play a significant role in leukocyte adhesion and infiltration from the peripheral blood into the inflamed tissues. As a result, various targeting ligands of CAMs have been exploited for selective delivery of active agents to specific inflamed tissues (e.g., neutrophil-membrane, $\gamma 3$ peptide, anti-ICAM- 1 antibody) (Table 3) [111-113]. As an example, by coating anti-CAM antibodies on bioresponsive NPs, Zhang et al. developed a nanocarrier system able to co-deliver antibiotic and antiinflammatory drugs to target infectious microenvironments (Figure 10A) [55]. This strategy has simultaneously enabled bacteria elimination and alleviated host inflammatory response in both acute lung bacterial infection and the sepsis mouse model.

In the case of intracellular bacterial infections, instead of targeting the bacteria, nanosystems were developed to target infected host cells through various types of specific receptors present on their surfaces. Additionally, the ideal ligands could promote intracellular delivery of NPs, then effectively deliver antibiotics to subcellular compartments containing bacteria. Various ligands have been exploited to functionalize the nanocarrier's surface for targeting infected host cells, such as mannose [57,121], dextran [103], folic acid [119], lectins [41], peptides [122,123], and bacterial membrane or its derivatives (mimicking bacterial phagocytosis) [116-118] (Table 3).

For example, immune cells including Kupffer cells, alveolar, peritoneal, splenic macrophages, dendritic cells, and a subset of vascular endothelial cells have been shown to express high levels of mannose receptors [124]. Therefore, mannosylated NPs have been used to deliver antibiotics more specifically to infected macrophages, as well as to infection sites through macrophage transport (macrophage hitchhiking). In this respect, Xiong et al. showed that the targeting efficiency of a mannosylated nanogel to macrophages was significantly higher than that of an unmodified nanogel in a zebrafish embryo model (Figure 10B) [57]. In addition, upon entering macrophages, the polyphosphoester crosslinked core of NPs was degraded by the phosphatase and phospholipase (secreted by MRSA during macrophage infection), resulting in the fast release of the antibiotic payload and the superior inhibition of intracellular bacterial growth.

In an innovative idea, Yang et al. proposed a strategy, namely, "Kill the Real with the Fake", using the membrane of extracellular vesicle (EV) secreted by bacteria as an active-targeting ligand for an antibiotic carrier (Figure 10C) [116]. Macrophages, after exposure to the bacterium, showed enhanced expression of various recognition receptors, allowing the greater innate immune response upon reinfection with the same type of pathogen. As a result, EV membrane coating of PLGA NPs endowed the particle with an active targeting capacity both in vitro and in vivo. Intravenous administration of antibioticloaded NPs coated with the EV membrane proved to be more efficient than free antibiotics and bare NPs in the kidney and lung, which bear the highest metastatic bacterial burden. The extended application of bacterial EVs has also been explored in several other studies, in which nanocarriers based on EVs (e.g., A. baumannii, E. coli) could protect antibiotics and increase their bacterial uptake $[125,126]$. However, potential toxicity induced by the EVs surface antigen and incorporated DNA components might concern the future translation of these biomimetic NP delivery systems. 
A.
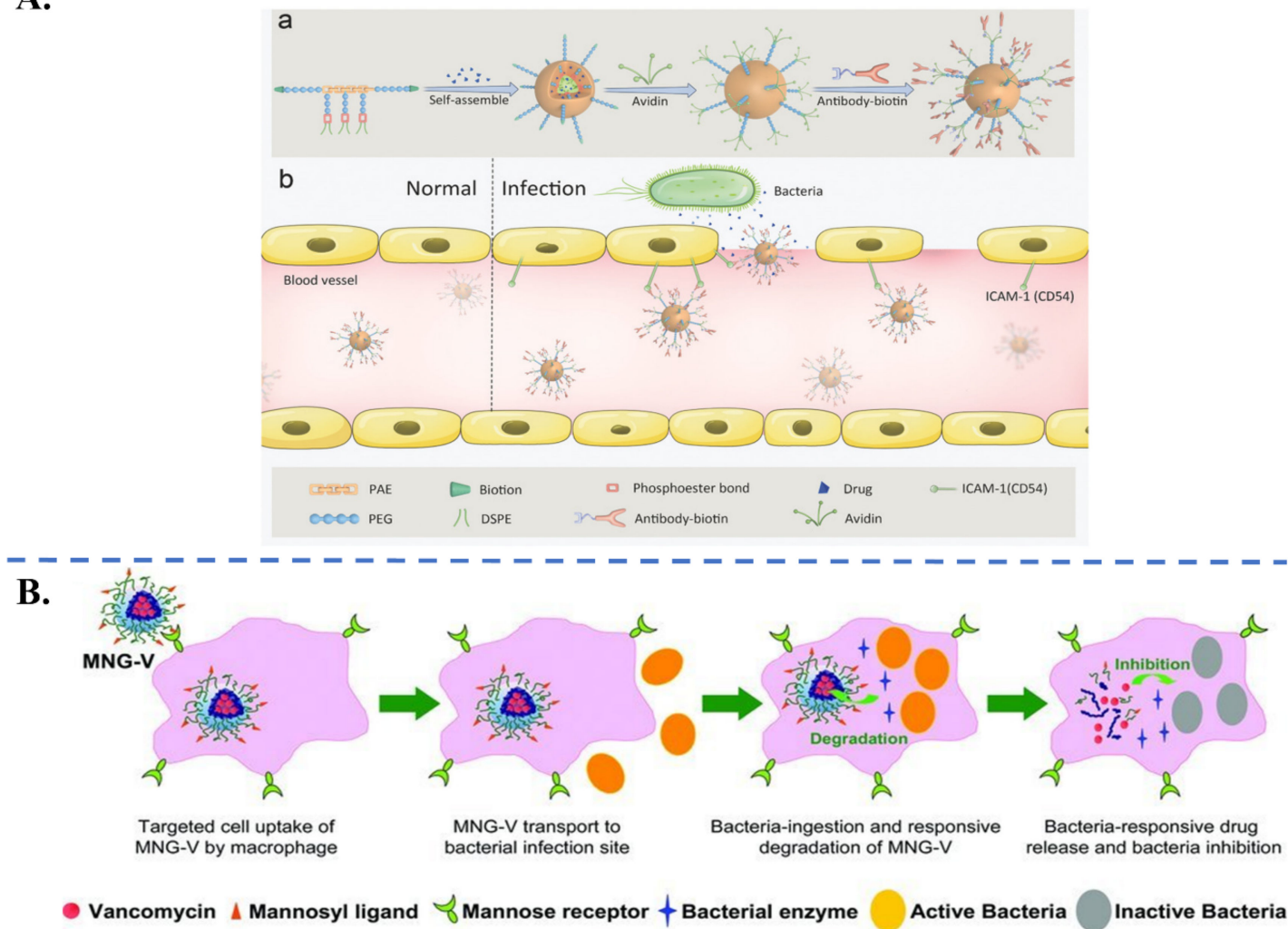

C.

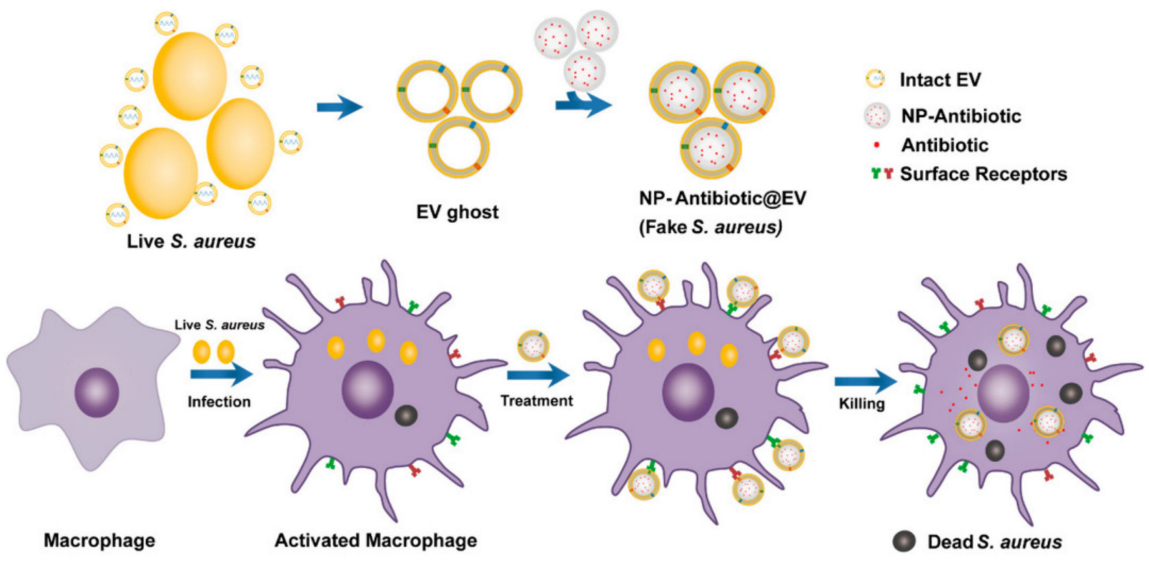

Figure 10. Active targeting of antibiotic-loaded nanocarriers to infectious microenvironment. (A) Schematic for the design of bioresponsive antibiotic-loaded NPs with a surface coating of ICAM-1 antibodies (a) and their action mechanisms (b). NPs specifically target activated endothelial cells at a site of infection after intravenous injection, then cross the blood vessel and release drugs triggered by the local infectious cues (pH/enzyme) (reprinted with permission from [55], copyright 2018 John Wiley and Sons). (B) Schematic illustration of the targeted uptake of mannosylated nanogels loaded with vancomycin (MNG-V) by macrophages and the responsive release of the antibiotic under the action of bacterial enzymes (reprinted with permission from [57], copyright 2012 John Wiley and Sons). (C) Schematic illustration on the preparation of NPs coated with the membrane of extracellular vesicle (EV) secreted by S. aureus as active-targeting antibiotic carrier. Because the nanocarrier is camouflaged with the membrane of $S$. aureus EV, S. aureus-infected macrophages may mistake NPs as S. aureus, leading to promoted NP internalization and, consequently, facilitated intracellular delivery of its drug cargoes (reprinted with permission from [116], copyright 2019 ACS). 


\section{Codelivery Platforms for Combination Antibiotic Therapy}

Drug combinations are the mainstay of antibiotic-resistant infection treatments by generating synergistic effects of two or more antimicrobial drugs. However, owing to different pharmacokinetics, the most current combination regimens do not guarantee that all antimicrobials arrive at the site of infection at the predetermined concentration range for maximum synergy.

In this regard, nanocarrier systems offer several advantages for multidrug delivery over the combination of free antibiotics. Co-encapsulation of the synergistic drug combination in the same carrier allows normalizing the pharmacokinetics of drugs with dissimilar physicochemical properties and stability. By using a targeting nanocarrier system, a precise drug-to-drug ratio can be directly delivered at the infectious site. In addition, the controlled release from nanocarriers also allows independent tuning of release rates of each drug optimally. This approach enables minimizing the amount of drug administered to achieve the desired synergistic effect, thereby reducing the side effects commonly encountered in drug combinations.

Depending on the physicochemical properties, combined drugs can be covalently linked to the polymer backbone or physically co-encapsulated into the polymeric cores through drug-polymer association to ensure the drug release rate and ratio in a controlled manner. Several polymeric nanocarrier systems have been reported for delivering drug combinations, including antibiotic-antibiotic combinations and the pairing of an antibiotic with a non-antibiotic adjuvant molecule, as summarized in Table 4.

Table 4. Examples of nanocarrier platforms for co-delivery of antibiotic combination.

\begin{tabular}{|c|c|c|c|c|c|}
\hline & Drug Combination & Nanocarrier & Co-Delivery Purpose & Targeted Bacteria & Ref. \\
\hline \multirow{7}{*}{ 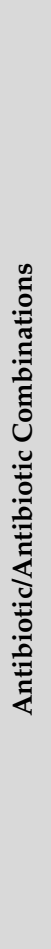 } & $\begin{array}{l}\text { Rifampicin, } \\
\text { Levofloxacin }\end{array}$ & Curdlan NPs & $\begin{array}{l}\text { Simultaneous sustained release } \\
\text { Targeted delivery }\end{array}$ & $\begin{array}{l}\text { Intracellular } M \text {. } \\
\text { smegmatis }\end{array}$ & [115] \\
\hline & $\begin{array}{l}\text { Four first-line anti-TB } \\
\text { drugs }\end{array}$ & PLGA NPs & $\begin{array}{l}\text { Reduction in dosing frequency } \\
\text { Improvements in patient compliance }\end{array}$ & $\begin{array}{l}\text { Intracellular } M \text {. } \\
\text { tuberculosis }\end{array}$ & [127] \\
\hline & $\begin{array}{l}\text { Streptomycin, } \\
\text { Doxycycline }\end{array}$ & $\begin{array}{c}\text { Polymeric } \\
\text { Nanocomplex }\end{array}$ & Synergistic antimicrobial effect & $\begin{array}{c}\text { Intracellular Brucella } \\
\text { melitensis }\end{array}$ & [128] \\
\hline & $\begin{array}{l}\text { Rifampin, } \\
\text { Azithromycin }\end{array}$ & PLGA NPs & $\begin{array}{l}\text { Enhanced intracellular and } \\
\text { intra-inclusion accumulation } \\
\text { Sustained drug release }\end{array}$ & $\begin{array}{l}\text { Intracellular } C . \\
\text { trachomatis }\end{array}$ & [129] \\
\hline & $\begin{array}{l}\text { Amoxicillin, } \\
\text { Clarithromycin, } \\
\text { Omeprazole }\end{array}$ & $\begin{array}{l}\text { Chitosan-glutamate } \\
\text { NPs }\end{array}$ & $\begin{array}{c}\text { Synergic effects } \\
\text { Reduction of effective dose }\end{array}$ & H. pylori & [130] \\
\hline & Colistin, Rifampicin & Micelle & Synergistic antimicrobial effect & $\begin{array}{l}\text { E. coli, } P \text {. aeruginosa, } A \text {. } \\
\text { baumannii }\end{array}$ & [25] \\
\hline & $\begin{array}{l}\text { Silver NPs, } \\
\text { Ampicillin }\end{array}$ & Polymersome & $\begin{array}{c}\text { Synergistic effect (at 1:0.64 ratio) } \\
\text { Drug protection from hydrolysis } \\
\text { by } \beta \text {-lactamase enzymes }\end{array}$ & Resistant E. coli & [131] \\
\hline
\end{tabular}


Table 4. Cont.

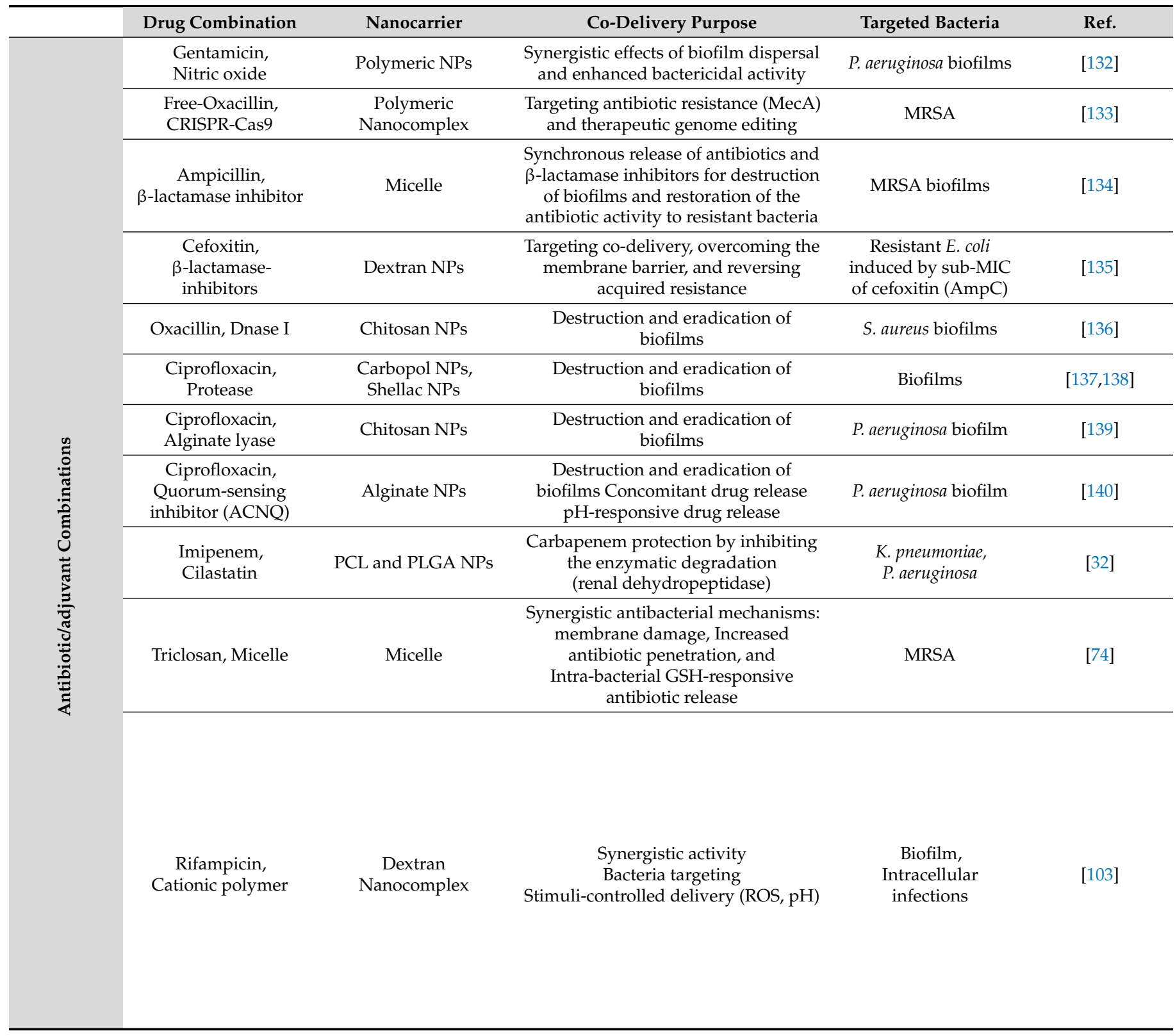

For example, the benefit of antibiotic combination therapies using polymeric nanocarriers has been reported for the treatment of infections caused by intracellular pathogens with combinations of up to four drugs such as $M$. tuberculosis (rifampicin, isoniazid, pyrazinamide, ethambutol) [127], Brucella melitensis (streptomycin, doxycycline) [128], and Chlamydia trachomatis (rifampin, azithromycin) [129]. Treatment of H. pylori infection requires a complex regimen including two antibiotics (clarithromycin, metronidazole, or amoxicillin) and one proton pump inhibitor. These drugs could be combined in a single nanocarrier formulation, improving patient compliance and reducing the time and dose required for the complete eradication of infection [130]. In another example described above, co-encapsulation of colistin and rifampicin in the micelles not only reduced systemic toxicity of colistin but also provided a synergistic antimicrobial effect against antibiotic-resistant strains of E. coli, P. aeruginosa, and A. baumannii [25].

In addition, nanocarrier systems have also been exploited to combine antibiotics with adjuvants (active molecules do not kill bacteria but instead enhance the effect of an antibiotic) (Table 4). A classic example of a commercial antibiotic-adjuvant combination 
is Augmentin, which combines a $\beta$-lactam antibiotic (amoxicillin) with a $\beta$-lactamase inhibitor (clavulanic acid). In this regard, Sun et al. recently developed a polymeric nanocarrier system based on benzoxaborole-conjugated dextran (a $\beta$-lactamase inhibitor macromolecule) for precise transport of $\beta$-lactam antibiotics to strains overexpressing $\beta$-lactamases (Figure 11A) [135]. Thanks to the high affinity of benzoxaborole with cis-diol structures on bacterial cell walls, the nanocarriers enabled specific recognition and rapid internalization toward bacteria and distinctly inhibited the catalytic activity of bacterially secreted $\beta$-lactamase. Using a wound infection model, the cefoxitin-loaded nanocarrier system significantly enhanced the ability to kill drug-resistant $E$. coli compared to the free-form drug by specifically overcoming the membrane barrier and acquired resistance mechanism of $\beta$-lactamase overproduction.

In another approach, the nanocarrier-based drug combination therapy has been widely applied for the treatment of biofilm infections by co-delivering antibiotics and biofilmdispersing enzymes, which are capable of degrading EPS components, such as proteins, eDNA, polysaccharides, or quorum-sensing molecules (Table 4) [136-139]. The dispersing compounds could revert the biofilm bacteria back to their planktonic growth mode, rendering bacteria susceptible to conventional antibiotics. On the other hand, the reduction in viscosity by enzyme activity potentially increased the penetration of antibiotics-loaded NPs into the deeper layers of the biofilm where persister cells reside. As a result, these dual-purpose nanocarriers could degrade the biofilm effectively, reduce biofilm biomass, and simultaneously enhance the antibiotic's effect.

Similarly, Gong et al. developed a multifunctional NP system that displays the synergistic activity of antimicrobial cationic polymer and antibiotics against antimicrobialresistant pathogens (Figure 11B) [103]. Besides the drug co-delivery purpose, the system possessed most nanocarrier-based strategies for localized antibiotic delivery, as mentioned in this review. Indeed, using dextran as a hydrophilic shell and poly( $\beta$-amino ester)guanidine-phenylboronic acid (PBAE-G-B) as hydrophobic core, the resulting NPs could encapsulate hydrophobic antibiotics (e.g., rifampicin) in a physiological environment. On the one side, the dextran shell possessed a strong affinity with lectins expressed by bacteria and macrophages, thereby enhancing the bioavailability of the NPs. On the other side, the PBAE-G-B could be responsive to both low $\mathrm{pH}$ and high ROS of the inflammatory microenvironment and converted to hydrophilic cationic polymers (PBAE-G) with potent antimicrobial activity. Subsequently, this hydrophobic/hydrophilic transition combined with the disruption of the phenylboronic ester bonds (second $\mathrm{pH} / \mathrm{ROS}$-responsive) between PBAE-G-B polymer and dextran destabilized the NPs, causing the simultaneous release of the cationic polymers and the antibiotic, thereby effectively killing the pathogens. As a result, the complex system effectively eliminated the biofilm and intracellular infections and exhibited efficacy against antibiotic-resistant bacteria (E. coli, P. aeruginosa, M. smegmatis, MRSA) in both in vitro and in vivo models. 
A.
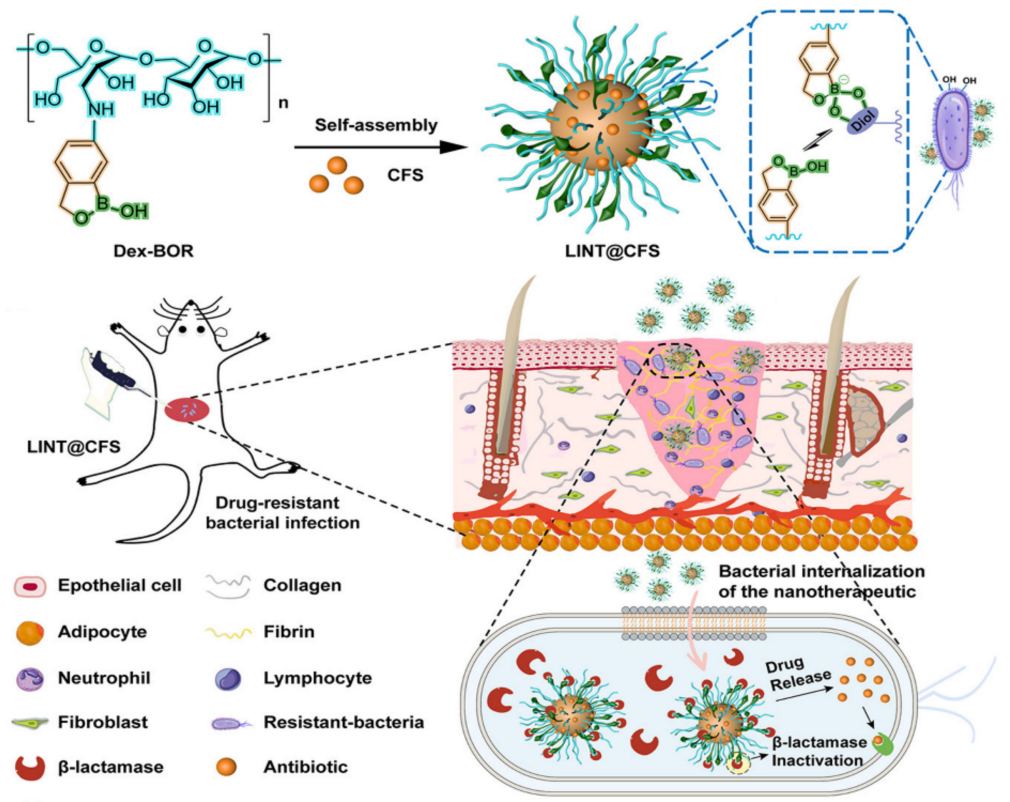

Penicillin-binding protein

Revitalization of antibiotic activity

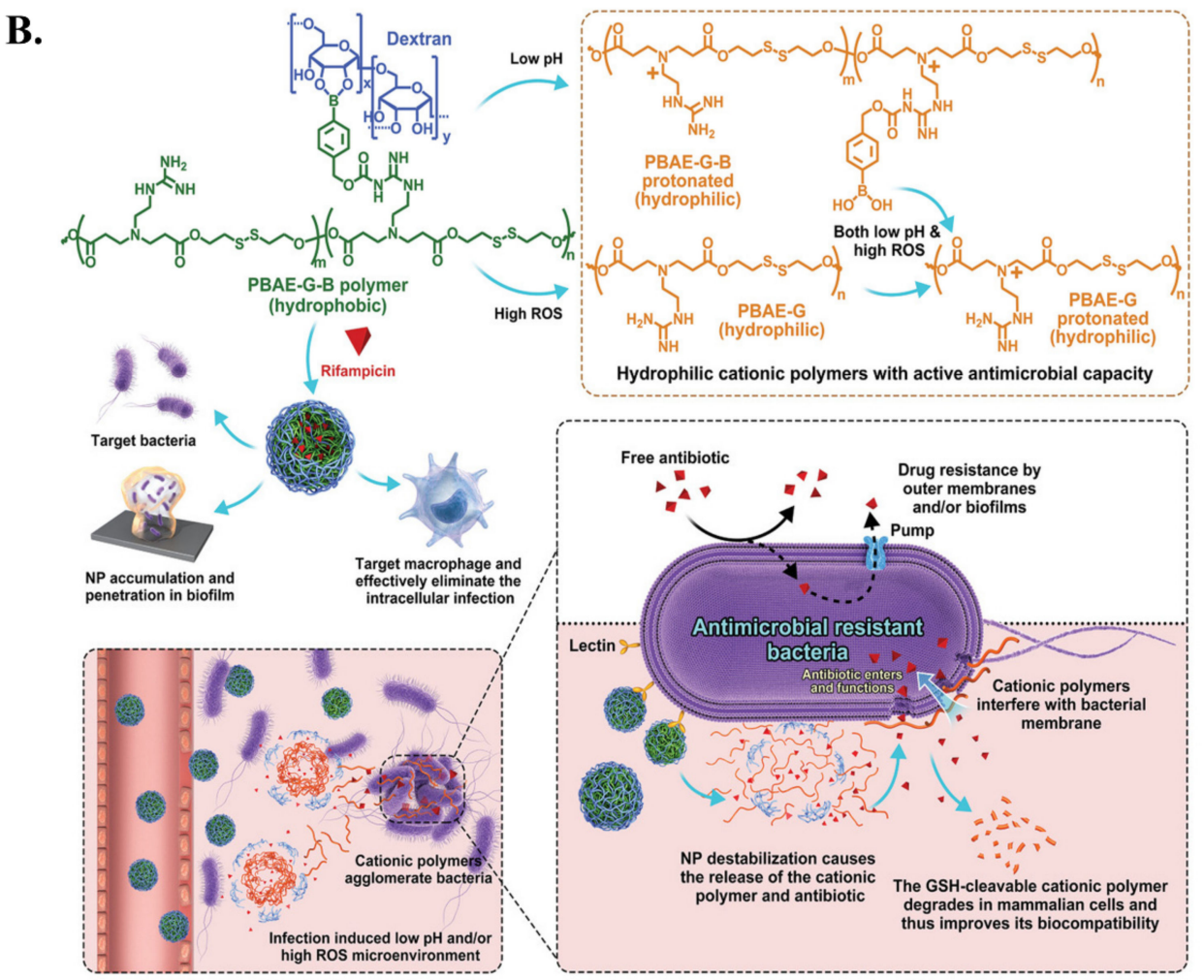

Figure 11. Examples of nanocarrier platforms for co-delivery of antibiotic combination. (A) Schematic Illustration of antibiotic-loaded nanocarrier with $\beta$-lactamase reversible, competitive inhibitory activity for the treatment of antibiotic-resistant, bacteria-infected wound (reprinted with permission from [135], copyright 2021 ACS). (B) Schematic illustration of the composition and the antibacterial mechanism of a multifunctional NP platform for co-delivery of antibiotic combination (Solubility enhancement, passive and active targeting delivery, $\mathrm{pH}$ - and ROS-responsive drug release, and codelivery of dual drugs) (reprinted with permission from [103], copyright 2021 John Wiley and Sons). 


\section{Discussions and Conclusions}

In this review, we reported advances in antibiotic delivery strategies based on polymer nanocarriers. A wide range of nano-platforms has been designed to overcome unfavorable physicochemical properties and the poor local bioavailability of several existing antibiotics, thereby ultimately improving their therapeutic features as well as slowing the emergence of drug resistance. Further, overcoming antibiotic resistance has also been accomplished by co-encapsulating therapeutic combinations in a single nanocarrier formulation, in which a synergistic antimicrobial effect has enhanced therapeutic efficacy.

However, despite these promising preclinical results, several challenges remain for clinical exploitation of nanocarriers-based antibiotic delivery strategies. The safety of nanomaterials in the human body is among the major barriers to the clinical use of these dosage forms.

Firstly, the safety of NPs depends on the administration route and their exposure (dose and duration) [141]. For instance, pulmonary administration minimizes systemic exposure to the nanocarrier formulation, thus bypassing the hepatic first-pass metabolism and increasing the delivery of the antibiotic cargo to the infected lung tissue. However, extensive exposure to nanomaterials through the lungs can induce excessive inflammatory responses and tissue necrosis [142].

For systemic administration, NPs can be distributed via the blood circulation to multiple organs, including the target site, and are simultaneously cleared by these organs [143]. Generally, during delivery of the antibiotic cargo, nanocarriers can simultaneously be metabolized (e.g., in the liver and spleen) or eliminated gradually (e.g., via renal filtration or biliary excretion) [144]. The fate of nanoparticles in the body depends on their physical and chemical properties, such as size, shape, and surface characteristics, which have been described in previous reviews $[145,146]$. Through these parameters, the blood circulation half-life of NPs can be tunable to achieve favorable outcomes. For example, the long circulation time of nano-formulations in the bloodstream can be positively correlated with clinical effectiveness like enhanced nanocarrier deposition in the infected site (passive targeting) or bactericidal activities of time-dependent antibiotics. However, the prolonged circulatory residence time of the NPs can also relate to long-term toxicity and other side effects in the body [147]. Therefore, the balance between circulation time and in vivo clearance after treatment is critical in designing antibiotic-loaded nanocarriers.

Although current animal models allow determining most of the pharmacokinetic profile of NPs to better understand their fate and behavior [143], several potential toxicities and long-term effects of nanomaterials may not be observed in preclinical trials. For instance, even where nanocarriers are derived from biodegradable polymers, the distribution and toxicity of their degradation products are challenging to determine experimentally [148]. Additionally, while the antimicrobial properties of nanomaterial and their degradation products on pathogenic bacteria are extensively reported, negative impacts on the human microbiota are not fully characterized. Therefore, a complete evaluation of both acute and long-term health risks of the polymer carrier materials (biopolymers and synthetic polymers) should be considered before designing novel drug delivery systems. In an ideal case, a nanocarrier formulation should degrade to uniform fragments that are considered of low toxicity and prone to rapid clearance out of the body.

In addition, technical aspects and the risk-cost-benefit ratio also restrict the clinical implementation of nano-formulation [149]. The fact is that current efforts are mainly focused on developing antibiotic-delivery systems with a high degree of complexity (multifunctional nanocarriers). This is not always necessary and sometimes outside the original nanomedicine purpose, which is to optimize the pharmacokinetic profile of the existing drugs with a simple, robust, and safe formulation. Although complex interventions are required to achieve a drug delivery system with high therapeutic efficiency, especially in order to overwhelm the resistance mechanisms of antibiotics, each additional layer of complexity raises concerns about side effect risks of the carrier, reproducibility, scalability, 
and rising manufacturing costs, eventually having a significant impact on the translation into the clinic.

Furthermore, in most of the potential nano-formulations mentioned in this review, carrier materials remain major components, leading to the drawback of low drug loading (typically less than $10 \%$ of the total weight). As a result, the use of such formulations with a large portion of inert materials may impose an extra burden for patients, including systemic toxicity and additional costs [150].

Therefore, besides the therapeutic goals, simplifying the structures of nanocarriers with minimal excipients should be taken into account during formulation development to ensure their successful clinical translation.

Overall, with the continuous advances in drug delivery and antibiotic discovery, we may expect that nanocarrier-based antibiotic formulation will be exploited as a common therapeutic practice in the near future, providing significant contributions to fighting bacterial infection.

Funding: H.L. was supported by a Ph.D. research scholarship from the Ministère de l'Enseignement Supérieur, de la Recherche et de l'Innovation.

Institutional Review Board Statement: Not applicable.

Informed Consent Statement: Not applicable.

Conflicts of Interest: The authors declare no conflict of interest.

\section{References}

1. Miethke, M.; Pieroni, M.; Weber, T.; Brönstrup, M.; Hammann, P.; Halby, L.; Arimondo, P.B.; Glaser, P.; Aigle, B.; Bode, H.B.; et al. Towards the sustainable discovery and development of new antibiotics. Nat. Rev. Chem. 2021, 5, 726-749. [CrossRef]

2. Ropponen, H.-K.; Richter, R.; Hirsch, A.K.H.; Lehr, C.-M. Mastering the Gram-negative bacterial barrier-Chemical approaches to increase bacterial bioavailability of antibiotics. Adv. Drug Deliv. Rev. 2021, 172, 339-360. [CrossRef]

3. Gao, W.; Chen, Y.; Zhang, Y.; Zhang, Q.; Zhang, L. Nanoparticle-based local antimicrobial drug delivery. Adv. Drug Deliv. Rev. 2018, 127, 46-57. [CrossRef]

4. $\quad$ Birk, S.E.; Boisen, A.; Nielsen, L.H. Polymeric nano- and microparticulate drug delivery systems for treatment of biofilms. Adv. Drug Deliv. Rev. 2021, 174, 30-52. [CrossRef] [PubMed]

5. Abed, N.; Couvreur, P. Nanocarriers for antibiotics: A promising solution to treat intracellular bacterial infections. Int. J. Antimicrob. Agents 2014, 43, 485-496. [CrossRef]

6. Blair, J.M.; Webber, M.A.; Baylay, A.J.; Ogbolu, D.O.; Piddock, L.J. Molecular mechanisms of antibiotic resistance. Nat. Rev. Microbiol. 2015, 13, 42-51. [CrossRef]

7. Hermsen, R.; Deris, J.B.; Hwa, T. On the rapidity of antibiotic resistance evolution facilitated by a concentration gradient. Proc. Natl. Acad. Sci. USA 2012, 109, 10775. [CrossRef] [PubMed]

8. Makabenta, J.M.V.; Nabawy, A.; Li, C.-H.; Schmidt-Malan, S.; Patel, R.; Rotello, V.M. Nanomaterial-based therapeutics for antibiotic-resistant bacterial infections. Nat. Rev. Microbiol. 2021, 19, 23-36. [CrossRef] [PubMed]

9. Kirtane, A.R.; Verma, M.; Karandikar, P.; Furin, J.; Langer, R.; Traverso, G. Nanotechnology approaches for global infectious diseases. Nat. Nanotechnol. 2021, 16, 369-384. [CrossRef] [PubMed]

10. Xiong, M.-H.; Bao, Y.; Yang, X.-Z.; Zhu, Y.-H.; Wang, J. Delivery of antibiotics with polymeric particles. Adv. Drug Deliv. Rev. 2014, 78, 63-76. [CrossRef] [PubMed]

11. Wang, Y.; Yang, Y.; Shi, Y.; Song, H.; Yu, C. Antibiotic-Free Antibacterial Strategies Enabled by Nanomaterials: Progress and Perspectives. Adv. Mater. 2020, 32, 1904106. [CrossRef] [PubMed]

12. Tsume, Y.; Mudie, D.M.; Langguth, P.; Amidon, G.E.; Amidon, G.L. The Biopharmaceutics Classification System: Subclasses for in vivo predictive dissolution (IPD) methodology and IVIVC. Eur. J. Pharm. Sci. 2014, 57, 152-163. [CrossRef] [PubMed]

13. Tehler, U.; Fagerberg, J.H.; Svensson, R.; Larhed, M.; Artursson, P.; Bergström, C.A.S. Optimizing Solubility and Permeability of a Biopharmaceutics Classification System (BCS) Class 4 Antibiotic Drug Using Lipophilic Fragments Disturbing the Crystal Lattice. J. Med. Chem. 2013, 56, 2690-2694. [CrossRef] [PubMed]

14. Durairaj, C.; Kadam, R.S.; Chandler, J.W.; Hutcherson, S.L.; Kompella, U.B. Nanosized Dendritic Polyguanidilyated Translocators for Enhanced Solubility, Permeability, and Delivery of Gatifloxacin. Investig. Ophthalmol. Vis. Sci. 2010, 51, 5804-5816. [CrossRef] [PubMed]

15. Yang, L.; Zhang, C.; Huang, F.; Liu, J.; Zhang, Y.; Yang, C.; Ren, C.; Chu, L.; Liu, B.; Liu, J. Triclosan-based supramolecular hydrogels as nanoantibiotics for enhanced antibacterial activity. J. Control. Release 2020, 324, 354-365. [CrossRef] [PubMed] 
16. Gheffar, C.; Le, H.; Jouenne, T.; Schaumann, A.; Corbière, A.; Vaudry, D.; LeCerf, D.; Karakasyan, C. Antibacterial Activity of Ciprofloxacin-Loaded Poly(lactic-co-glycolic acid)-Nanoparticles Against Staphylococcus aureus. Part. Part. Syst. Charact. 2021, 38, 2000253. [CrossRef]

17. Kalita, S.; Devi, B.; Kandimalla, R.; Sharma, K.K.; Sharma, A.; Kalita, K.; Kataki, A.C.; Kotoky, J. Chloramphenicol encapsulated in

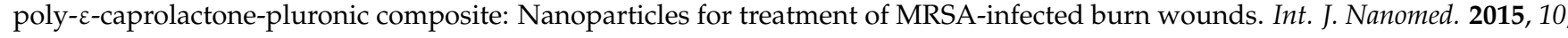
2971-2984.

18. Masood, F.; Yasin, T.; Bukhari, H.; Mujahid, M. Characterization and application of roxithromycin loaded cyclodextrin based nanoparticles for treatment of multidrug resistant bacteria. Mater. Sci. Eng. C 2016, 61, 1-7. [CrossRef]

19. Horev, B.; Klein, M.I.; Hwang, G.; Li, Y.; Kim, D.; Koo, H.; Benoit, D.S. pH-activated nanoparticles for controlled topical delivery of farnesol to disrupt oral biofilm virulence. ACS Nano 2015, 9, 2390-2404. [CrossRef] [PubMed]

20. Landis, R.F.; Gupta, A.; Lee, Y.-W.; Wang, L.-S.; Golba, B.; Couillaud, B.; Ridolfo, R.; Das, R.; Rotello, V.M. Cross-Linked Polymer-Stabilized Nanocomposites for the Treatment of Bacterial Biofilms. ACS Nano 2017, 11, 946-952. [CrossRef] [PubMed]

21. Rahbar Takrami, S.; Ranji, N.; Sadeghizadeh, M. Antibacterial effects of curcumin encapsulated in nanoparticles on clinical isolates of Pseudomonas aeruginosa through downregulation of efflux pumps. Mol. Biol. Rep. 2019, 46, 2395-2404. [CrossRef]

22. Magana, M.; Pushpanathan, M.; Santos, A.L.; Leanse, L.; Fernandez, M.; Ioannidis, A.; Giulianotti, M.A.; Apidianakis, Y.; Bradfute, S.; Ferguson, A.L.; et al. The value of antimicrobial peptides in the age of resistance. Lancet Infect. Dis. 2020, 20, e216-e230. [CrossRef]

23. Ndayishimiye, J.; Popat, A.; Blaskovich, M.; Falconer, J.R. Formulation technologies and advances for oral delivery of novel nitroimidazoles and antimicrobial peptides. J. Control. Release 2020, 324, 728-749. [CrossRef]

24. Rishi, P.; Bhogal, A.; Arora, S.; Pandey, S.K.; Verma, I.; Kaur, I.P. Improved oral therapeutic potential of nanoencapsulated cryptdin formulation against Salmonella infection. Eur. J. Pharm. Sci. 2015, 72, 27-33. [CrossRef]

25. Yang, X.; Ren, H.; Zhang, H.; Liu, G.; Jiang, Z.; Qiu, Q.; Yu, C.; Murthy, N.; Zhao, K.; Lovell, J.F.; et al. Antibiotic Cross-linked Micelles with Reduced Toxicity for Multidrug-Resistant Bacterial Sepsis Treatment. ACS Appl. Mater. Interfaces 2021, 13, 9630-9642. [CrossRef]

26. Jani, S.; Ramirez, M.S.; Tolmasky, M.E. Silencing Antibiotic Resistance with Antisense Oligonucleotides. Biomedicines 2021, 9, 416. [CrossRef] [PubMed]

27. González-Paredes, A.; Sitia, L.; Ruyra, A.; Morris, C.J.; Wheeler, G.N.; McArthur, M.; Gasco, P. Solid lipid nanoparticles for the delivery of anti-microbial oligonucleotides. Eur. J. Pharm. Biopharm. 2019, 134, 166-177. [CrossRef]

28. Bikard, D.; Barrangou, R. Using CRISPR-Cas systems as antimicrobials. Curr. Opin. Microbiol. 2017, 37, 155-160. [CrossRef]

29. Edson, J.A.; Kwon, Y.J. RNAi for silencing drug resistance in microbes toward development of nanoantibiotics. J. Control. Release 2014, 189, 150-157. [CrossRef]

30. Perche, F.; le Gall, T.; Montier, T.; Pichon, C.; Malinge, J.-M. Cardiolipin-Based Lipopolyplex Platform for the Delivery of Diverse Nucleic Acids into Gram-Negative Bacteria. Pharmaceuticals 2019, 12, 81. [CrossRef]

31. Greenhalgh, K.; Turos, E. In vivo studies of polyacrylate nanoparticle emulsions for topical and systemic applications. Nanomedicine 2009, 5, 46-54. [CrossRef]

32. Shaaban, M.I.; Shaker, M.A.; Mady, F.M. Imipenem/cilastatin encapsulated polymeric nanoparticles for destroying carbapenemresistant bacterial isolates. J. Nanobiotechnol. 2017, 15, 29. [CrossRef] [PubMed]

33. Le, H.; Arnoult, C.; Dé, E.; Schapman, D.; Galas, L.; le Cerf, D.; Karakasyan, C. Antibody-Conjugated Nanocarriers for Targeted Antibiotic Delivery: Application in the Treatment of Bacterial Biofilms. Biomacromolecules 2021, 22, 1639-1653. [CrossRef] [PubMed]

34. Gao, P.; Nie, X.; Zou, M.; Shi, Y.; Cheng, G. Recent advances in materials for extended-release antibiotic delivery system. J. Antibiot. 2011, 64, 625-634. [CrossRef] [PubMed]

35. Peng, K.-T.; Chen, C.-F.; Chu, I.M.; Li, Y.-M.; Hsu, W.-H.; Hsu, R.W.-W.; Chang, P.-J. Treatment of osteomyelitis with teicoplaninencapsulated biodegradable thermosensitive hydrogel nanoparticles. Biomaterials 2010, 31, 5227-5236. [CrossRef]

36. Yus, C.; Irusta, S.; Sebastian, V.; Arruebo, M. Controlling Particle Size and Release Kinetics in the Sustained Delivery of Oral Antibiotics Using pH-Independent Mucoadhesive Polymers. Mol. Pharm. 2020, 17, 3314-3327. [CrossRef]

37. Kamaly, N.; Yameen, B.; Wu, J.; Farokhzad, O.C. Degradable Controlled-Release Polymers and Polymeric Nanoparticles: Mechanisms of Controlling Drug Release. Chem. Rev. 2016, 116, 2602-2663. [CrossRef] [PubMed]

38. Zhang, Y.; Zhang, J.; Chen, M.; Gong, H.; Thamphiwatana, S.; Eckmann, L.; Gao, W.; Zhang, L. A Bioadhesive NanoparticleHydrogel Hybrid System for Localized Antimicrobial Drug Delivery. ACS Appl. Mater. Interfaces 2016, 8, 18367-18374. [CrossRef] [PubMed]

39. Dillen, K.; Vandervoort, J.; van den Mooter, G.; Ludwig, A. Evaluation of ciprofloxacin-loaded Eudragit ${ }^{\circledR}$ RS100 or RL100/PLGA nanoparticles. Int. J. Pharm. 2006, 314, 72-82. [CrossRef]

40. Zhang, F.; Smolen, J.A.; Zhang, S.; Li, R.; Shah, P.N.; Cho, S.; Wang, H.; Raymond, J.E.; Cannon, C.L.; Wooley, K.L. Degradable polyphosphoester-based silver-loaded nanoparticles as therapeutics for bacterial lung infections. Nanoscale 2015, 7, 2265-2270. [CrossRef] [PubMed]

41. Sharma, A.; Sharma, S.; Khuller, G.K. Lectin-functionalized poly (lactide-co-glycolide) nanoparticles as oral/aerosolized antitubercular drug carriers for treatment of tuberculosis. J. Antimicrob. Chemother. 2004, 54, 761-766. [CrossRef] 
42. Lueth, P.; Haughney, S.L.; Binnebose, A.M.; Mullis, A.S.; Peroutka-Bigus, N.; Narasimhan, B.; Bellaire, B.H. Nanotherapeutic provides dose sparing and improved antimicrobial activity against Brucella melitensis infections. J. Control. Release 2019, 294, 288-297. [CrossRef]

43. Piras, A.M.; Maisetta, G.; Sandreschi, S.; Esin, S.; Gazzarri, M.; Batoni, G.; Chiellini, F. Preparation, physical-chemical and biological characterization of chitosan nanoparticles loaded with lysozyme. Int. J. Biol. Macromol. 2014, 67, 124-131. [CrossRef]

44. Van Bambeke, F.; Barcia-Macay, M.; Lemaire, S.; Tulkens, P.M. Cellular pharmacodynamics and pharmacokinetics of antibiotics: Current views and perspectives. Curr. Opin. Drug Discov. Dev. 2006, 9, 218-230.

45. Levison, M.E.; Levison, J.H. Pharmacokinetics and pharmacodynamics of antibacterial agents. Infect. Dis. Clin. N. Am. 2009, 23, 791-815. [CrossRef] [PubMed]

46. Maji, R.; Omolo, C.A.; Agrawal, N.; Maduray, K.; Hassan, D.; Mokhtar, C.; Mackhraj, I.; Govender, T. pH-Responsive LipidDendrimer Hybrid Nanoparticles: An Approach To Target and Eliminate Intracellular Pathogens. Mol. Pharm. 2019, 16, 4594-4609. [CrossRef]

47. Sonawane, S.J.; Kalhapure, R.S.; Jadhav, M.; Rambharose, S.; Mocktar, C.; Govender, T. AB2-type amphiphilic block copolymer containing a pH-cleavable hydrazone linkage for targeted antibiotic delivery. Int. J. Pharm. 2020, 575, 118948. [CrossRef] [PubMed]

48. Chai, M.; Gao, Y.; Liu, J.; Deng, Y.; Hu, D.; Jin, Q.; Ji, J. Polymyxin B-Polysaccharide Polyion Nanocomplex with Improved Biocompatibility and Unaffected Antibacterial Activity for Acute Lung Infection Management. Adv. Healthc. Mater. 2020, 9, 1901542. [CrossRef]

49. Lin, Y.-H.; Chang, C.-H.; Wu, Y.-S.; Hsu, Y.-M.; Chiou, S.-F.; Chen, Y.-J. Development of pH-responsive chitosan/heparin nanoparticles for stomach-specific anti-Helicobacter pylori therapy. Biomaterials 2009, 30, 3332-3342. [CrossRef] [PubMed]

50. Lane, D.D.; Su, F.Y.; Chiu, D.Y.; Srinivasan, S.; Wilson, J.T.; Ratner, D.M.; Stayton, P.S.; Convertine, A.J. Dynamic intracellular delivery of antibiotics via pH-responsive polymersomes. Polym. Chem. 2015, 6, 1255-1266. [CrossRef] [PubMed]

51. Lunn, A.M.; Unnikrishnan, M.; Perrier, S. Dual pH-Responsive Macrophage-Targeted Isoniazid Glycoparticles for Intracellular Tuberculosis Therapy. Biomacromolecules 2021, 22, 3756-3768. [CrossRef]

52. Arif, M.; Dong, Q.-J.; Raja, M.A.; Zeenat, S.; Chi, Z.; Liu, C.-G. Development of novel pH-sensitive thiolated chitosan/PMLA nanoparticles for amoxicillin delivery to treat Helicobacter pylori. Mater. Sci. Eng. C 2018, 83, 17-24. [CrossRef] [PubMed]

53. Chang, C.-H.; Lin, Y.-H.; Yeh, C.-L.; Chen, Y.-C.; Chiou, S.-F.; Hsu, Y.-M.; Chen, Y.-S.; Wang, C.-C. Nanoparticles Incorporated in pH-Sensitive Hydrogels as Amoxicillin Delivery for Eradication of Helicobacter pylori. Biomacromolecules 2010, 11, 133-142. [CrossRef] [PubMed]

54. Chen, M.; Xie, S.; Wei, J.; Song, X.; Ding, Z.; Li, X. Antibacterial Micelles with Vancomycin-Mediated Targeting and pH/LipaseTriggered Release of Antibiotics. ACS Appl. Mater. Interfaces 2018, 10, 36814-36823. [CrossRef]

55. Zhang, C.Y.; Gao, J.; Wang, Z. Bioresponsive Nanoparticles Targeted to Infectious Microenvironments for Sepsis Management. Adv. Mater. 2018, 30, 1803618. [CrossRef]

56. Su, Y.; Zhao, L.; Meng, F.; Qiao, Z.; Yao, Y.; Luo, J. Triclosan loaded polyurethane micelles with pH and lipase sensitive properties for antibacterial applications and treatment of biofilms. Mater. Sci. Eng. C 2018, 93, 921-930. [CrossRef] [PubMed]

57. Xiong, M.-H.; Li, Y.-J.; Bao, Y.; Yang, X.-Z.; Hu, B.; Wang, J. Bacteria-Responsive Multifunctional Nanogel for Targeted Antibiotic Delivery. Adv. Mater. 2012, 24, 6175-6180. [CrossRef] [PubMed]

58. Xiong, M.-H.; Bao, Y.; Yang, X.-Z.; Wang, Y.-C.; Sun, B.; Wang, J. Lipase-Sensitive Polymeric Triple-Layered Nanogel for “On-Demand" Drug Delivery. J. Am. Chem. Soc. 2012, 134, 4355-4362. [CrossRef] [PubMed]

59. Mir, M.; Ahmed, N.; Permana, A.D.; Rodgers, A.M.; Donnelly, R.F.; Rehman, A.U. Enhancement in Site-Specific Delivery of Carvacrol against Methicillin Resistant Staphylococcus aureus Induced Skin Infections Using Enzyme Responsive Nanoparticles: A Proof of Concept Study. Pharmaceutics 2019, 11, 606. [CrossRef] [PubMed]

60. Qi, G.-B.; Zhang, D.; Liu, F.-H.; Qiao, Z.-Y.; Wang, H. An “On-Site Transformation” Strategy for Treatment of Bacterial Infection. Adv. Mater. 2017, 29, 1703461. [CrossRef]

61. Li, Y.; Liu, G.; Wang, X.; Hu, J.; Liu, S. Enzyme-Responsive Polymeric Vesicles for Bacterial-Strain-Selective Delivery of Antimicrobial Agents. Angew. Chem. Int. Ed. 2016, 55, 1760-1764. [CrossRef]

62. Chu, L.; Gao, H.; Cheng, T.; Zhang, Y.; Liu, J.; Huang, F.; Yang, C.; Shi, L.; Liu, J. A charge-adaptive nanosystem for prolonged and enhanced in vivo antibiotic delivery. Chem. Commun. 2016, 52, 6265-6268. [CrossRef] [PubMed]

63. Gao, Y.; Wang, J.; Chai, M.; Li, X.; Deng, Y.; Jin, Q.; Ji, J. Size and Charge Adaptive Clustered Nanoparticles Targeting the Biofilm Microenvironment for Chronic Lung Infection Management. ACS Nano 2020, 14, 5686-5699. [CrossRef] [PubMed]

64. Baier, G.; Cavallaro, A.; Vasilev, K.; Mailänder, V.; Musyanovych, A.; Landfester, K. Enzyme Responsive Hyaluronic Acid Nanocapsules Containing Polyhexanide and Their Exposure to Bacteria to Prevent Infection. Biomacromolecules 2013, 14, 1103-1112. [CrossRef] [PubMed]

65. Wu, Y.; Long, Y.; Li, Q.-L.; Han, S.; Ma, J.; Yang, Y.-W.; Gao, H. Layer-by-Layer (LBL) Self-Assembled Biohybrid Nanomaterials for Efficient Antibacterial Applications. ACS Appl. Mater. Interfaces 2015, 7, 17255-17263. [CrossRef]

66. Ji, H.; Dong, K.; Yan, Z.; Ding, C.; Chen, Z.; Ren, J.; Qu, X. Bacterial Hyaluronidase Self-Triggered Prodrug Release for ChemoPhotothermal Synergistic Treatment of Bacterial Infection. Small 2016, 12, 6200-6206. [CrossRef] 
67. Baier, G.; Cavallaro, A.; Friedemann, K.; Müller, B.; Glasser, G.; Vasilev, K.; Landfester, K. Enzymatic degradation of poly(l-lactide) nanoparticles followed by the release of octenidine and their bactericidal effects. Nanomedicine 2014, 10, 131-139. [CrossRef] [PubMed]

68. Insua, I.; Liamas, E.; Zhang, Z.; Peacock, A.F.; Krachler, A.M.; Fernandez-Trillo, F. Enzyme-responsive polyion complex (PIC) nanoparticles for the targeted delivery of antimicrobial polymers. Polym. Chem. 2016, 7, 2684-2690. [CrossRef]

69. Hernandez, F.J.; Hernandez, L.I.; Kavruk, M.; Arıca, Y.M.; Bayramoğlu, G.; Borsa, B.A.; Öktem, H.A.; Schäfer, T.; Özalp, V.C. NanoKeepers: Stimuli responsive nanocapsules for programmed specific targeting and drug delivery. Chem. Commun. 2014, 50, 9489-9492. [CrossRef]

70. Wu, Y.; Song, Z.; Wang, H.; Han, H. Endogenous stimulus-powered antibiotic release from nanoreactors for a combination therapy of bacterial infections. Nat. Commun. 2019, 10, 4464. [CrossRef]

71. Zhao, Y.; Zhu, Y.; Yang, G.; Xia, L.; Yu, F.; Chen, C.; Zhang, L.; Cao, H. A pH/ $\mathrm{H}_{2} \mathrm{O}_{2}$ dual triggered nanoplatform for enhanced photodynamic antibacterial efficiency. J. Mater. Chem. B 2021, 9, 5076-5082. [CrossRef]

72. Wang, Y.; Yuan, Q.; Feng, W.; Pu, W.; Ding, J.; Zhang, H.; Li, X.; Yang, B.; Dai, Q.; Cheng, L.; et al. Targeted delivery of antibiotics to the infected pulmonary tissues using ROS-responsive nanoparticles. J. Nanobiotechnol. 2019, 17, 103. [CrossRef] [PubMed]

73. Zhang, Y.; Zhang, J.; Chen, W.; Angsantikul, P.; Spiekermann, K.A.; Fang, R.H.; Gao, W.; Zhang, L. Erythrocyte membranecoated nanogel for combinatorial antivirulence and responsive antimicrobial delivery against Staphylococcus aureus infection. J. Control. Release 2017, 263, 185-191. [CrossRef]

74. Cao, B.; Xiao, F.; Xing, D.; Hu, X. Polyprodrug Antimicrobials: Remarkable Membrane Damage and Concurrent Drug Release to Combat Antibiotic Resistance of Methicillin-Resistant Staphylococcus aureus. Small 2018, 14, 1802008. [CrossRef] [PubMed]

75. Lu, C.; Xiao, Y.; Liu, Y.; Sun, F.; Qiu, Y.; Mu, H.; Duan, J. Hyaluronic acid-based levofloxacin nanomicelles for nitric oxide-triggered drug delivery to treat bacterial infections. Carbohydr. Polym. 2020, 229, 115479. [PubMed]

76. Wong, P.T.; Tang, S.; Mukherjee, J.; Tang, K.; Gam, K.; Isham, D.; Murat, C.; Sun, R.; Baker, J.R.; Choi, S.K. Light-controlled active release of photocaged ciprofloxacin for lipopolysaccharide-targeted drug delivery using dendrimer conjugates. Chem. Commun. 2016, 52, 10357-10360. [CrossRef] [PubMed]

77. Gao, G.; Jiang, Y.-W.; Jia, H.-R.; Wu, F.-G. Near-infrared light-controllable on-demand antibiotics release using thermo-sensitive hydrogel-based drug reservoir for combating bacterial infection. Biomaterials 2019, 188, 83-95.

78. Chiang, W.-L.; Lin, T.-T.; Sureshbabu, R.; Chia, W.-T.; Hsiao, H.-C.; Liu, H.-Y.; Yang, C.-M.; Sung, H.-W. A rapid drug release system with a NIR light-activated molecular switch for dual-modality photothermal/antibiotic treatments of subcutaneous abscesses. J. Control. Release 2015, 199, 53-62. [CrossRef]

79. Di, J.; Kim, J.; Hu, Q.; Jiang, X.; Gu, Z. Spatiotemporal drug delivery using laser-generated-focused ultrasound system. J. Control. Release 2015, 220, 592-599. [CrossRef]

80. Huo, S.; Zhao, P.; Shi, Z.; Zou, M.; Yang, X.; Warszawik, E.; Loznik, M.; Göstl, R.; Herrmann, A. Mechanochemical bond scission for the activation of drugs. Nat. Chem. 2021, 13, 131-139.

81. Hua, X.; Tan, S.; Bandara, H.M.H.N.; Fu, Y.; Liu, S.; Smyth, H.D.C. Externally Controlled Triggered-Release of Drug from PLGA Micro and Nanoparticles. PLoS ONE 2014, 9, e114271. [CrossRef]

82. Sirivisoot, S.; Harrison, B.S. Magnetically stimulated ciprofloxacin release from polymeric microspheres entrapping iron oxide nanoparticles. Int. J. Nanomed. 2015, 10, 4447-4458. [CrossRef]

83. Mohapatra, A.; Harris, M.A.; LeVine, D.; Ghimire, M.; Jennings, J.A.; Morshed, B.I.; Haggard, W.O.; Bumgardner, J.D.; Mishra, S.R.; Fujiwara, T. Magnetic stimulus responsive vancomycin drug delivery system based on chitosan microbeads embedded with magnetic nanoparticles. J. Biomed. Mater. Res. Part B Appl. Biomater. 2018, 106, 2169-2176. [CrossRef]

84. Kumari, P.; Kulkarni, A.; Sharma, A.K.; Chakrapani, H. Visible-Light Controlled Release of a Fluoroquinolone Antibiotic for Antimicrobial Photopharmacology. ACS Omega 2018, 3, 2155-2160. [CrossRef]

85. Hamblin, M.R.; Hasan, T. Photodynamic therapy: A new antimicrobial approach to infectious disease? Photochem. Photobiol. Sci. 2004, 3, 436-450. [CrossRef]

86. Boissenot, T.; Bordat, A.; Fattal, E.; Tsapis, N. Ultrasound-triggered drug delivery for cancer treatment using drug delivery systems: From theoretical considerations to practical applications. J. Control. Release 2016, 241, 144-163. [CrossRef]

87. Cai, Y.; Wang, J.; Liu, X.; Wang, R.; Xia, L. A Review of the Combination Therapy of Low Frequency Ultrasound with Antibiotics. BioMed Res. Int. 2017, 2017, 2317846. [CrossRef] [PubMed]

88. Azzopardi, E.A.; Ferguson, E.L.; Thomas, D.W. The enhanced permeability retention effect: A new paradigm for drug targeting in infection. J. Antimicrob. Chemother. 2013, 68, 257-274. [CrossRef] [PubMed]

89. Petros, R.A.; DeSimone, J.M. Strategies in the design of nanoparticles for therapeutic applications. Nat. Rev. Drug Discov. 2010, 9 , 615-627. [CrossRef] [PubMed]

90. Golombek, S.K.; May, J.-N.; Theek, B.; Appold, L.; Drude, N.; Kiessling, F.; Lammers, T. Tumor targeting via EPR: Strategies to enhance patient responses. Adv. Drug Deliv. Rev. 2018, 130, 17-38. [CrossRef]

91. Fang, J.; Nakamura, H.; Maeda, H. The EPR effect: Unique features of tumor blood vessels for drug delivery, factors involved, and limitations and augmentation of the effect. Adv. Drug Deliv. Rev. 2011, 63, 136-151. [CrossRef] [PubMed]

92. Bakker-Woudenberg, I.A.J.M.; Lokerse, A.F.; ten Kate, M.T.; Mouton, J.W.; Woodle, M.C.; Storm, G. Liposomes with Prolonged Blood Circulation and Selective Localization in Klebsiella pneumoniae-Infected Lung Tissue. J. Infect. Dis. 1993, 168, 164-171. [CrossRef] [PubMed] 
93. Fontana, G.; Licciardi, M.; Mansueto, S.; Schillaci, D.; Giammona, G. Amoxicillin-loaded polyethylcyanoacrylate nanoparticles: Influence of PEG coating on the particle size, drug release rate and phagocytic uptake. Biomaterials 2001, 22, 2857-2865. [CrossRef]

94. Blanco, E.; Shen, H.; Ferrari, M. Principles of nanoparticle design for overcoming biological barriers to drug delivery. Nat. Biotechnol. 2015, 33, 941. [CrossRef] [PubMed]

95. Radovic-Moreno, A.F.; Lu, T.K.; Puscasu, V.A.; Yoon, C.J.; Langer, R.; Farokhzad, O.C. Surface Charge-Switching Polymeric Nanoparticles for Bacterial Cell Wall-Targeted Delivery of Antibiotics. ACS Nano 2012, 6, 4279-4287. [CrossRef]

96. Kell, A.J.; Stewart, G.; Ryan, S.; Peytavi, R.; Boissinot, M.; Huletsky, A.; Bergeron, M.G.; Simard, B. Vancomycin-Modified Nanoparticles for Efficient Targeting and Preconcentration of Gram-Positive and Gram-Negative Bacteria. ACS Nano 2008, 2, 1777-1788. [CrossRef]

97. Wong, P.T.; Tang, S.; Tang, K.; Coulter, A.; Mukherjee, J.; Gam, K.; Baker, J.R.; Choi, S.K. A lipopolysaccharide binding heteromultivalent dendrimer nanoplatform for Gram negative cell targeting. J. Mater. Chem. B 2015, 3, 1149-1156. [CrossRef]

98. Jiang, H.; Xiong, M.; Bi, Q.; Wang, Y.; Li, C. Self-enhanced targeted delivery of a cell wall- and membrane-active antibiotics, daptomycin, against staphylococcal pneumonia. Acta Pharm. Sin. B 2016, 6, 319-328. [CrossRef] [PubMed]

99. Yang, S.; Han, X.; Yang, Y.; Qiao, H.; Yu, Z.; Liu, Y.; Wang, J.; Tang, T. Bacteria-Targeting Nanoparticles with MicroenvironmentResponsive Antibiotic Release to Eliminate Intracellular Staphylococcus aureus and Associated Infection. ACS Appl. Mater. Interfaces 2018, 10, 14299-14311. [CrossRef]

100. Eissa, A.M.; Abdulkarim, A.; Sharples, G.J.; Cameron, N.R. Glycosylated Nanoparticles as Efficient Antimicrobial Delivery Agents. Biomacromolecules 2016, 17, 2672-2679. [CrossRef]

101. Zhao, Y.; Yu, C.; Yu, Y.; Wei, X.; Duan, X.; Dai, X.; Zhang, X. Bioinspired Heteromultivalent Ligand-Decorated Nanotherapeutic for Enhanced Photothermal and Photodynamic Therapy of Antibiotic-Resistant Bacterial Pneumonia. ACS Appl. Mater. Interfaces 2019, 11, 39648-39661. [CrossRef]

102. Michaud, G.; Visini, R.; Bergmann, M.; Salerno, G.; Bosco, R.; Gillon, E.; Richichi, B.; Nativi, C.; Imberty, A.; Stocker, A.; et al. Overcoming antibiotic resistance in Pseudomonas aeruginosa biofilms using glycopeptide dendrimers. Chem. Sci. 2016, 7, 166-182. [CrossRef]

103. Ye, M.; Zhao, Y.; Wang, Y.; Zhao, M.; Yodsanit, N.; Xie, R.; Andes, D.; Gong, S. A Dual-Responsive Antibiotic-Loaded Nanoparticle Specifically Binds Pathogens and Overcomes Antimicrobial-Resistant Infections. Adv. Mater. 2021, 33, 2006772. [CrossRef]

104. Kavruk, M.; Celikbicak, O.; Ozalp, V.C.; Borsa, B.A.; Hernandez, F.J.; Bayramoglu, G.; Salih, B.; Arica, M.Y. Antibiotic loaded nanocapsules functionalized with aptamer gates for targeted destruction of pathogens. Chem. Commun. 2015, 51, 8492-8495. [CrossRef] [PubMed]

105. Hussain, S.; Joo, J.; Kang, J.; Kim, B.; Braun, G.B.; She, Z.-G.; Kim, D.; Mann, A.P.; Mölder, T.; Teesalu, T.; et al. Antibiotic-loaded nanoparticles targeted to the site of infection enhance antibacterial efficacy. Nat. Biomed. Eng. 2018, 2, 95-103. [CrossRef]

106. Pang, X.; Liu, X.; Cheng, Y.; Zhang, C.; Ren, E.; Liu, C.; Zhang, Y.; Zhu, J.; Chen, X.; Liu, G. Sono-Immunotherapeutic Nanocapturer to Combat Multidrug-Resistant Bacterial Infections. Adv. Mater. 2019, 31, 1902530. [CrossRef]

107. Long, Y.; Li, Z.; Bi, Q.; Deng, C.; Chen, Z.; Bhattachayya, S.; Li, C. Novel polymeric nanoparticles targeting the lipopolysaccharides of Pseudomonas aeruginosa. Int. J. Pharm. 2016, 502, 232-241. [CrossRef] [PubMed]

108. Hu, C.-M.J.; Fang, R.H.; Wang, K.-C.; Luk, B.T.; Thamphiwatana, S.; Dehaini, D.; Nguyen, P.; Angsantikul, P.; Wen, C.H.; Kroll, A.V.; et al. Nanoparticle biointerfacing by platelet membrane cloaking. Nature 2015, 526, 118. [CrossRef] [PubMed]

109. Wang, C.; Wang, Y.; Zhang, L.; Miron, R.J.; Liang, J.; Shi, M.; Mo, W.; Zheng, S.; Zhao, Y.; Zhang, Y. Pretreated MacrophageMembrane-Coated Gold Nanocages for Precise Drug Delivery for Treatment of Bacterial Infections. Adv. Mater. 2018, 30, 1804023. [CrossRef]

110. Angsantikul, P.; Thamphiwatana, S.; Zhang, Q.; Spiekermann, K.; Zhuang, J.; Fang, R.H.; Gao, W.; Obonyo, M.; Zhang, L. Coating Nanoparticles with Gastric Epithelial Cell Membrane for Targeted Antibiotic Delivery against Helicobacter pylori Infection. Adv. Ther. 2018, 1, 1800016. [CrossRef]

111. Gao, J.; Wang, S.; Dong, X.; Leanse, L.G.; Dai, T.; Wang, Z. Co-delivery of resolvin D1 and antibiotics with nanovesicles to lungs resolves inflammation and clears bacteria in mice. Commun. Biol. 2020, 3, 680. [CrossRef]

112. Gao, J.; Dong, X.; Su, Y.; Wang, Z. Human neutrophil membrane-derived nanovesicles as a drug delivery platform for improved therapy of infectious diseases. Acta Biomater. 2021, 123, 354-363. [CrossRef]

113. Yang, Y.; Ding, Y.; Fan, B.; Wang, Y.; Mao, Z.; Wang, W.; Wu, J. Inflammation-targeting polymeric nanoparticles deliver sparfloxacin and tacrolimus for combating acute lung sepsis. J. Control. Release 2020, 321, 463-474. [CrossRef] [PubMed]

114. Chu, D.; Gao, J.; Wang, Z. Neutrophil-Mediated Delivery of Therapeutic Nanoparticles across Blood Vessel Barrier for Treatment of Inflammation and Infection. ACS Nano 2015, 9, 11800-11811. [CrossRef] [PubMed]

115. Yunus Basha, R.; TS, S.K.; Doble, M. Dual delivery of tuberculosis drugs via cyclodextrin conjugated curdlan nanoparticles to infected macrophages. Carbohydr. Polym. 2019, 218, 53-62. [CrossRef] [PubMed]

116. Gao, F.; Xu, L.; Yang, B.; Fan, F.; Yang, L. Kill the Real with the Fake: Eliminate Intracellular Staphylococcus aureus Using Nanoparticle Coated with Its Extracellular Vesicle Membrane as Active-Targeting Drug Carrier. ACS Infect. Dis. 2019, 5, $218-227$. [CrossRef] [PubMed]

117. Menina, S.; Labouta, H.I.; Geyer, R.; Krause, T.; Gordon, S.; Dersch, P.; Lehr, C.-M. Invasin-functionalized liposome nanocarriers improve the intracellular delivery of anti-infective drugs. RSC Adv. 2016, 6, 41622-41629. [CrossRef] 
118. Labouta, H.I.; Menina, S.; Kochut, A.; Gordon, S.; Geyer, R.; Dersch, P.; Lehr, C.-M. Bacteriomimetic invasin-functionalized nanocarriers for intracellular delivery. J. Control. Release 2015, 220, 414-424. [CrossRef]

119. Benchaala, I.; Mishra, M.K.; Wykes, S.M.; Hali, M.; Kannan, R.M.; Whittum-Hudson, J.A. Folate-functionalized dendrimers for targeting Chlamydia-infected tissues in a mouse model of reactive arthritis. Int. J. Pharm. 2014, 466, 258-265. [CrossRef]

120. Lehar, S.M.; Pillow, T.; Xu, M.; Staben, L.; Kajihara, K.K.; Vandlen, R.; DePalatis, L.; Raab, H.; Hazenbos, W.L.; Hiroshi Morisaki, J.; et al. Novel antibody-antibiotic conjugate eliminates intracellular S. aureus. Nature 2015, $527,323$. [CrossRef]

121. Moretton, M.A.; Chiappetta, D.A.; Andrade, F.; das Neves, J.; Ferreira, D.; Sarmento, B.; Sosnik, A. Hydrolyzed GalactomannanModified Nanoparticles and Flower-Like Polymeric Micelles for the Active Targeting of Rifampicin to Macrophages. J. Biomed. Nanotechnol. 2013, 9, 1076-1087. [CrossRef]

122. Brezden, A.; Mohamed, M.F.; Nepal, M.; Harwood, J.S.; Kuriakose, J.; Seleem, M.N.; Chmielewski, J. Dual Targeting of Intracellular Pathogenic Bacteria with a Cleavable Conjugate of Kanamycin and an Antibacterial Cell-Penetrating Peptide. J. Am. Chem. Soc. 2016, 138, 10945-10949. [CrossRef]

123. Agarwal, A.; Kandpal, H.; Gupta, H.P.; Singh, N.B.; Gupta, C.M. Tuftsin-bearing liposomes as rifampin vehicles in treatment of tuberculosis in mice. Antimicrob. Agents Chemother. 1994, 38, 588-593. [CrossRef]

124. Kawakami, S.; Hashida, M. Glycosylation-mediated targeting of carriers. J. Control. Release 2014, 190, 542-555. [CrossRef] [PubMed]

125. Huang, W.; Zhang, Q.; Li, W.; Yuan, M.; Zhou, J.; Hua, L.; Chen, Y.; Ye, C.; Ma, Y. Development of novel nanoantibiotics using an outer membrane vesicle-based drug efflux mechanism. J. Control. Release 2020, 317, 1-22. [CrossRef]

126. Wu, S.; Huang, Y.; Yan, J.; Li, Y.; Wang, J.; Yang, Y.Y.; Yuan, P.; Ding, X. Bacterial Outer Membrane-Coated Mesoporous Silica Nanoparticles for Targeted Delivery of Antibiotic Rifampicin against Gram-Negative Bacterial Infection In Vivo. Adv. Funct. Mater. 2021, 31, 2103442. [CrossRef]

127. Pandey, R.; Khuller, G.K. Oral nanoparticle-based antituberculosis drug delivery to the brain in an experimental model. J. Antimicrob. Chemother. 2006, 57, 1146-1152. [CrossRef] [PubMed]

128. Seleem, M.N.; Jain, N.; Pothayee, N.; Ranjan, A.; Riffle, J.S.; Sriranganathan, N. Targeting Brucella melitensis with polymeric nanoparticles containing streptomycin and doxycycline. FEMS Microbiol. Lett. 2009, 294, 24-31. [CrossRef]

129. Toti, U.S.; Guru, B.R.; Hali, M.; McPharlin, C.M.; Wykes, S.M.; Panyam, J.; Whittum-Hudson, J.A. Targeted delivery of antibiotics to intracellular chlamydial infections using PLGA nanoparticles. Biomaterials 2011, 32, 6606-6613. [CrossRef] [PubMed]

130. Ramteke, S.; Ganesh, N.; Bhattacharya, S.; Jain, N.K. Amoxicillin, clarithromycin, and omeprazole based targeted nanoparticles for the treatment of H. pylori. J. Drug Target. 2009, 17, 225-234. [CrossRef] [PubMed]

131. Geilich, B.M.; van de Ven, A.L.; Singleton, G.L.; Sepúlveda, L.J.; Sridhar, S.; Webster, T.J. Silver nanoparticle-embedded polymersome nanocarriers for the treatment of antibiotic-resistant infections. Nanoscale 2015, 7, 3511-3519. [CrossRef] [PubMed]

132. Nguyen, T.-K.; Selvanayagam, R.; Ho, K.K.K.; Chen, R.; Kutty, S.K.; Rice, S.A.; Kumar, N.; Barraud, N.; Duong, H.T.T.; Boyer, C. Co-delivery of nitric oxide and antibiotic using polymeric nanoparticles. Chem. Sci. 2016, 7, 1016-1027. [CrossRef] [PubMed]

133. Kang, Y.K.; Kwon, K.; Ryu, J.S.; Lee, H.N.; Park, C.; Chung, H.J. Nonviral Genome Editing Based on a Polymer-Derivatized CRISPR Nanocomplex for Targeting Bacterial Pathogens and Antibiotic Resistance. Bioconjug. Chem. 2017, 28, 957-967. [CrossRef] [PubMed]

134. Chen, M.; Qiu, B.; Zhang, Z.; Xie, S.; Liu, Y.; Xia, T.; Li, X. Light-triggerable and pH/lipase-responsive release of antibiotics and $\beta$-lactamase inhibitors from host-guest self-assembled micelles to combat biofilms and resistant bacteria. Chem. Eng. J. 2021, 424, 130330. [CrossRef]

135. Sun, H.; Yu, Y.; Zhang, Y.; Li, J.; Cheng, Y.; Huang, S.; Wang, W.; Zhang, X. Glycosylated Nanotherapeutics with $\beta$-Lactamase Reversible Competitive Inhibitory Activity Reinvigorates Antibiotics against Gram-Negative Bacteria. Biomacromolecules 2021, 22, 2834-2849. [CrossRef]

136. Tan, Y.; Ma, S.; Leonhard, M.; Moser, D.; Haselmann, G.M.; Wang, J.; Eder, D.; Schneider-Stickler, B. Enhancing antibiofilm activity with functional chitosan nanoparticles targeting biofilm cells and biofilm matrix. Carbohydr. Polym. 2018, 200, 35-42. [CrossRef]

137. Weldrick, P.J.; Hardman, M.J.; Paunov, V.N. Enhanced Clearing of Wound-Related Pathogenic Bacterial Biofilms Using ProteaseFunctionalized Antibiotic Nanocarriers. ACS Appl. Mater. Interfaces 2019, 11, 43902-43919. [CrossRef]

138. Weldrick, P.J.; Hardman, M.J.; Paunov, V.N. Smart active antibiotic nanocarriers with protease surface functionality can overcome biofilms of resistant bacteria. Mater. Chem. Front. 2021, 5, 961-972. [CrossRef]

139. Patel, K.K.; Tripathi, M.; Pandey, N.; Agrawal, A.K.; Gade, S.; Anjum, M.M.; Tilak, R.; Singh, S. Alginate lyase immobilized chitosan nanoparticles of ciprofloxacin for the improved antimicrobial activity against the biofilm associated mucoid P. aeruginosa infection in cystic fibrosis. Int. J. Pharm. 2019, 563, 30-42. [CrossRef]

140. Singh, N.; Romero, M.; Travanut, A.; Monteiro, P.F.; Jordana-Lluch, E.; Hardie, K.R.; Williams, P.; Alexander, M.R.; Alexander, C. Dual bioresponsive antibiotic and quorum sensing inhibitor combination nanoparticles for treatment of Pseudomonas aeruginosa biofilms in vitro and ex vivo. Biomater. Sci. 2019, 7, 4099-4111. [CrossRef]

141. Najahi-Missaoui, W.; Arnold, R.D.; Cummings, B.S. Safe Nanoparticles: Are We There Yet? Int. J. Mol. Sci. 2020, $22,385$. [CrossRef]

142. Grabowski, N.; Hillaireau, H.; Vergnaud, J.; Santiago, L.A.; Kerdine-Romer, S.; Pallardy, M.; Tsapis, N.; Fattal, E. Toxicity of surface-modified PLGA nanoparticles toward lung alveolar epithelial cells. Int. J. Pharm. 2013, 454, 686-694. [CrossRef] [PubMed] 
143. Bertrand, N.; Leroux, J.-C. The journey of a drug-carrier in the body: An anatomo-physiological perspective. J. Control. Release 2012, 161, 152-163. [CrossRef] [PubMed]

144. Wyss, P.P.; Lamichhane, S.P.; Abed, A.; Vonwil, D.; Kretz, O.; Huber, T.B.; Sarem, M.; Shastri, V.P. Renal clearance of polymeric nanoparticles by mimicry of glycan surface of viruses. Biomaterials 2020, 230, 119643. [CrossRef] [PubMed]

145. Alexis, F.; Pridgen, E.; Molnar, L.K.; Farokhzad, O.C. Factors Affecting the Clearance and Biodistribution of Polymeric Nanoparticles. Mol. Pharm. 2008, 5, 505-515. [CrossRef]

146. Mitchell, M.J.; Billingsley, M.M.; Haley, R.M.; Wechsler, M.E.; Peppas, N.A.; Langer, R. Engineering precision nanoparticles for drug delivery. Nat. Rev. Drug Discov. 2021, 20, 101-124. [CrossRef]

147. Wei, Y.; Quan, L.; Zhou, C.; Zhan, Q. Factors relating to the biodistribution \& clearance of nanoparticles \& their effects on in vivo application. Nanomedicine 2018, 13, 1495-1512. [PubMed]

148. Liechty, W.B.; Kryscio, D.R.; Slaughter, B.V.; Peppas, N.A. Polymers for drug delivery systems. Annu. Rev. Chem. Biomol. Eng. 2010, 1, 149-173. [CrossRef]

149. Leroux, J.-C. Editorial: Drug Delivery: Too Much Complexity, Not Enough Reproducibility? Angew. Chem. Int. Ed. 2017, 56, 15170-15171. [CrossRef]

150. Shen, S.; Wu, Y.; Liu, Y.; Wu, D. High drug-loading nanomedicines: Progress, current status, and prospects. Int. J. Nanomed. 2017, 12, 4085-4109. [CrossRef] 